\title{
The burden of common variable immunodeficiency disorders: a retrospective analysis of the European Society for Immunodeficiency (ESID) registry data
}

Irina Odnoletkova ${ }^{1,2,11^{*}}$, Gerhard Kindle ${ }^{3,4}$, Isabella Quinti ${ }^{5,6}$, Bodo Grimbacher ${ }^{4,7}$, Viviane Knerr ${ }^{3,4}$, Benjamin Gathmann ${ }^{3,4}$, Stephan Ehl ${ }^{3,4}$, Nizar Mahlaoui ${ }^{8,9,10}$, Philippe Van Wilder ${ }^{11}$, Kris Bogaerts ${ }^{12,13}$, Esther de Vries ${ }^{14,15}$ in collaboration with the Plasma Protein Therapeutics Association (PPTA) Taskforce

\footnotetext{
Abstract

Background: Common variable immunodeficiency disorders (CVID) are a group of rare innate disorders characterized by specific antibody deficiency and increased rates of infections, comorbidities and mortality. The burden of CVID in Europe has not been previously estimated. We performed a retrospective analysis of the European Society for Immunodeficiencies (ESID) registry data on the subset of patients classified by their immunologist as CVID and treated between 2004 and 2014. The registered deaths and comorbidities were used to calculate the annual average agestandardized rates of Years of Life Lost to premature death (YLL), Years Lost to Disability (YLD) and Disability Adjusted Life Years $(D A L Y=Y L L+Y L D)$. These outcomes were expressed as a rate per $10^{5}$ of the CVID cohort (the individual disease burden), and of the general population (the societal disease burden).

Results: Data of 2700 patients from 23 countries were analysed. Annual comorbidity rates: bronchiectasis, 21.9\%; autoimmunity, 23.2\%; digestive disorders, 15.6\%; solid cancers, 5.5\%; lymphoma, 3.8\%, exceeded the prevalence in the general population by a factor of 34.0, 7.6, 8.1, 2.4 and 32.6, respectively. The comorbidities of CVID caused 8722 (6069; $12,363) \mathrm{YLD} / 10^{5}$ in this cohort, whereas $44 \%$ of disability burden was attributable to infections and bronchiectasis. The total individual burden of CVID was 36,785 $(33,078,41,380)$ DALY/105. With estimated CVID prevalence of $\sim 1 / 25,000$, the societal burden of CVID ensued $1.5(1.3,1.7) \mathrm{DALY} / 10^{5}$ of the general population.

In exploratory analysis, increased mortality was associated with solid tumor, $\operatorname{HR}(95 \% \mathrm{Cl}): 2.69(1.10 ; 6.57) p=0.030$, lymphoma: $5.48(2.36 ; 12.71) p<.0001$ and granulomatous-lymphocytic interstitial lung disease: $4.85(1.63 ; 14.39) p=0.005$. Diagnostic delay (median: 4 years) was associated with a higher risk of death: $1.04(1.02 ; 1.06) p=.0003$, bronchiectasis: 1.03 $(1.01 ; 1.04) p=.0001$, solid tumor: $1.08(1.04 ; 1.11) p<.0001$ and enteropathy: $1.02(1.00 ; 1.05) p=.0447$ and stayed unchanged over four decades $(p=.228)$.

(Continued on next page)
}

\footnotetext{
* Correspondence: irina.v.odnoletkova@gmail.com

'Plasma Protein Therapeutics Association, Boulevard Brand Whitlock 114b4,

1200 Brussels, Belgium

${ }^{2}$ Faculty of Medicine and Health Sciences, Ghent University, C. Heymanslaan

10, 9000 Ghent, Belgium

Full list of author information is available at the end of the article
}

(c) The Author(s). 2018 Open Access This article is distributed under the terms of the Creative Commons Attribution 4.0 International License (http://creativecommons.org/licenses/by/4.0/), which permits unrestricted use, distribution, and reproduction in any medium, provided you give appropriate credit to the original author(s) and the source, provide a link to the Creative Commons license, and indicate if changes were made. The Creative Commons Public Domain Dedication waiver (http://creativecommons.org/publicdomain/zero/1.0/) applies to the data made available in this article, unless otherwise stated. 
(Continued from previous page)

Conclusions: While the societal burden of CVID may seem moderate, it is severe to the individual patient. Delay in CVID diagnosis may constitute a modifiable risk factor of serious comorbidities and death but showed no improvement. Tools supporting timely CVID diagnosis should be developed with high priority.

Keywords: Primary immunodeficiency, Primary antibody deficiency, Common variable immunodeficiency, Burden of disease, DALY, Health economics, Diagnostic delay

\section{Introduction}

Common variable immunodeficiency disorders (CVID) constitute a heterogeneous immune defect characterized by hypogammaglobulinemia, failure of specific antibody production, susceptibility to infections, and an array of comorbidities [1,2]. CVID is one of the most prevalent types of primary immunodeficiencies, occurring in about 1 : 25,000 of the population, equally affecting men and women [3-6]. CVID is typically characterized by significantly decreased levels of IgG, in combination with decreased IgA and/or IgM, poor vaccine response, and increased susceptibility to bacterial infections [3, 7]. A peak in the onset of symptoms falls in the first and third decades of life [3]. CVID can occur at any age but should not be diagnosed before the age of four, because other primary immunodeficiencies or transient hypogammaglobulinemia of infancy are at first difficult to distinguish and more likely in young infants $[3,7]$. Although a full unanimity regarding the definition of CVID does not exist at this point, a recent International Consensus on Common Variable Immunodeficiency Disorders (ICON) offers a good framework for the diagnosis of CVID [3].

CVID is associated with high comorbidity and increased mortality [2-4, 8-13]. The most prominent clinical problems in CVID observed at diagnosis and during follow-up are recurrent respiratory tract infections, such as chronic sinusitis, chronic otitis media, bronchitis and pneumonia $[7,14,15]$.

Complications of CVID can be divided into structural damage due to severe and/or recurrent infections such as bronchiectasis, and the consequences of the immune dysregulation $[2,10]$. The latter 'non-infectious' complications of CVID are autoimmune and autoinflammatory conditions, such as cytopenias, granulomas, gastrointestinal inflammatory disease, enteropathy and splenomegaly [3, 9]. CVID is also associated with a higher prevalence of solid tumours and lymphoid malignancies [9]. In the past 40 years, the standard treatment of CVID has been immunoglobulin replacement therapy. It commenced with intramuscular products, which were abandoned once safe intravenous (IVIG) and subcutaneous (SCIG) therapies were introduced [9]. Recent research advocates the individualization of the immunoglobulin dose, depending not so much on trough IgG levels but on the incidence of infections [15-17].
The survival of people with CVID improved from about 30\% 12 years after diagnosis reported in the first studied UK cohort in 1969 [18], to 58\% 45 years after diagnosis as shown in a recent analysis [2]. Such improvements are believed to be associated with a better understanding of the disease, widespread usage of IgG replacement therapy and improved anti-microbial therapies, together resulting in a reduced incidence of severe infections [3, 10, 15-17, 19]. However, morbidity and mortality remain grave concerns for CVID patients $[2,3,13]$. The most common causes of death in CVID are reported to be respiratory failure from chronic lung disease, lymphomas and other cancers [3, 20]. Overall survival of people with CVID continues to be less than that of age-matched controls $[3,12,20]$.

The burden of CVID in Europe in terms of loss of healthy life years due to premature death and disability has not been previously estimated. Burden of disease studies provide the initial indication of how the systems of care affect patient outcomes. The methodology for such burden of disease analysis was developed by the World Health Organization (WHO) and applied in a range of studies published as "Global Burden of Disease Study" ("GBD”) [21]. GBD uses Disability Adjusted Life Years (DALYs) as a common metric for the quantification of health loss, calculated as a sum of life years lost to premature mortality and life years lost to disability. DALYs allow for direct comparison of burden across diseases and geographic areas. Regular re-assessment of the burden of disease is crucial to track the evolution in clinical outcomes, to assess treatment and/or prevention campaigns results, and to define health service and research priorities. Moreover, results of burden of disease studies provide input for health economic evaluations of healthcare interventions.

GBD studies already analyzed the burden of more than 300 conditions across the globe, however, the burden of many rare diseases remains unknown. The objective of this research was to estimate the burden of CVID by using the data of the European Society for Immunodeficiencies (ESID) registry, the largest primary immunodeficiency registry in the world [22]. Despite certain limitations common to registry data in general, such as incomplete documentation and quality control [11], the ESID registry provides a 
valuable source of information for a burden of CVID analysis, due to the large size of the cohort.

\section{Methods \\ Design}

Retrospective analysis of the ESID registry data subset of patients classified as CVID by an immunologist and treated between 2004 and 2014.

\section{ESID registry}

ESID registry is an electronic database for a uniform collection of demographic, clinical and immunological data on patients with primary immunodeficiency, established in 2004. The immunological treatment centres from most European countries contributed patient data to this database. The data from the patients' clinical files were entered in the registry manually by treatment centre assistants. The registry is technically maintained at the Centre for Chronic Immunodeficiency, University Medical Centre Freiburg, Germany. The included patients signed a consent form (https://esid.org/Working-Parties/ Registry/Informed-Patient-Consent). The data extraction was performed by the registry custodian (GK) based on CVID classification established by the immunological treatment centre and upon approval of the study design by the ESID Registry Steering Committee (Additional file 1: Overview of the ESID registry data used in this study).

\section{Patient inclusion}

Patients were included in the analysis if within the ESID registry, they were classified as CVID by their treating immunologist ${ }^{1}$; with diagnosis of CVID established or confirmed after 4 years of age; and if they were treated in a centre between 2004 and 2014; and at least the following data were available: sex, country of origin, year of birth, year of CVID diagnosis, follow-up period. Patients with 'old' records, i.e. preceding the year of the ESID registry setup (2004) were not included.

\section{Data quality assessment}

To exclude unreliable data from the analysis, the data found in the registry were examined for consistency with the coding rules. For numerical data, such as year of birth, visit date and Ig dose, a plausible range was established a priori; for the weight outcomes in children, the WHO child growth statistics were used [23]. Consistency of the ICD-10 codes and the textual descriptions of comorbidities and infections was checked. Unreliable or inconsistent data were removed and analysed as 'missing'.

\section{Outcomes}

Mortality, Years of Life Lost to premature death (YLL), prevalence of comorbidities, Years Lost due to Disability (YLD) and Disability Adjusted Life Years (DALY) in the ESID cohort were analysed over the period 2004-2014 and compared with the respective outcomes in the general population in Europe. Mortality rate was defined as average annual all-cause mortality rate. YLL were computed by multiplying the number of deaths in each age subgroup by the standard life expectancy at that age. The division in age subgroups was based on a 5-year age interval; age, sex, and country specific healthy life expectancy statistics were used [24].

YLD were estimated based on the GBD methodology: within the GBD studies, disability weights for above 300 conditions were estimated and assigned an index between 0 and 1 , wherein 1 is associated with death and 0 with perfect health; annual YLD rate was then calculated as the prevalence of a condition in a particular year multiplied by the respective disability weight [25]. YLD associated with CVID was computed as a sum of YLDs caused by CVID comorbidities. YLD due to each comorbidity identified in the CVID cohort was calculated as follows: annual average YLD rate over the study period (2004-2014) in the general population as reported by the GBD study, divided by the annual average prevalence rate of the respective comorbidity in the general population over the same period, and multiplied by the annual average registration rate in the CVID cohort.

The registration rate of non-infectious and infectious comorbidities was derived from the respective subsets of patients with registered comorbidities by using the total number of patients in these subsets as denominator [11]. Non-infectious comorbidities were grouped as follows: bronchiectasis; granulomatous-lymphocytic interstitial lung disease (GLILD); splenomegaly; autoimmunity (cytopenias; and organ/systemic); granuloma (other than GLILD); enteropathy; solid tumor; lymphoma; lymphoproliferation; other chronic lung disease (asthma, COPD, emphysema) [2, 3, 9-11]. Infections were grouped in serious bacterial infections, such as pneumonia and meningitis [26]; and other infections, according to the GBD classification: lower respiratory (e.g. bronchitis); upper respiratory (e.g. sinusitis); otitis media; diarrhea; varicella/herpes zoster; other [24, 27].

Total individual disease burden was defined as annual average age-standardized DALY calculated as the sum of YLL and YLD rates per $10^{5}$ in this cohort. The societal disease burden, i.e. health loss caused by CVID per $10^{5}$ of general population, was calculated as DALY rate in the CVID cohort multiplied by the estimated CVID prevalence in Europe. The individual and societal 
burden of CVID and ten major causes of health loss in Europe were compared [24].

\section{Statistical analysis}

The analyses were performed with SAS, version 9.4. Baseline characteristics were summarized by mean, standard deviation, median and range for continuous variables, and by numbers and percentages for categorical variables. The following formulas were applied: a) Annual death rate per $10^{5}=(\mathrm{N}$ of deaths in year $\mathrm{X}) /(\mathrm{N}$ of people in the cohort in year X) $\times 10^{5}$; b) Age-specific death rate $=(\mathrm{N}$ of deaths in year $\mathrm{X}$ in age group $\mathrm{Y}$ ) / ( $\mathrm{N}$ of people in the cohort in year $\mathrm{X}$ in age group $\mathrm{Y}) \times 10^{5}$; c) Age-adjusted death rate $=\Sigma((\mathrm{N}$ of deaths in year $\mathrm{X}$ in age group $\mathrm{Y}) /(\mathrm{N}$ of people in the cohort in year $\mathrm{X}$ in age group $\mathrm{Y}) \times 10^{5} \mathrm{x}$ Proportion of age group $\mathrm{Y}$ in world population).

The period prevalence of comorbidities was computed as number of cases with a comorbidity registered at least once during the follow-up period divided by the number of all patients in the subset with registered comorbidities. The annual prevalence over the period of 2004-2014 was computed by using a multiple imputation methodology for missing years of the diagnosis of the registered comorbidities and infections. Ten imputations for the missing year of a comorbidity or infection were drawn from a uniform distribution between the year of diagnosis and the last year of follow-up. If the duration of the infection was missing, it was sampled from a Poisson distribution mimicking the distribution of the durations of the observed infections. Age-standardization was performed by using the WHO world population standard [21].

All-cause mortality since time point of diagnosis was estimated using a Cox proportional hazards model with Efron's method of tie handling and accommodating for left truncation (entry from 2004). The follow-up period was computed as the year of the last record minus the year of the CVID diagnosis. Association between survival and the following variables was explored: sex, age at diagnosis, age at onset, diagnostic delay, parental consanguinity, monthly Ig replacement dosage, prevalence of comorbidities. These associations were tested by means of univariable analysis and as bivariable analysis after adjustment for the age of CVID and the age of CVID symptoms onset, respectively. Diagnostic delay was explored as factor of the prevalence of comorbidities. Results were summarized by means of the hazard ratio (HR) and a 95\% confidence interval (CI). Comorbidities and monthly Ig replacement dosage were handled as a time-dependent covariate. For the calculation of the mean monthly relative Ig dose, all registered dosages were converted in $\mathrm{mg} / \mathrm{kg}$. If only absolute Ig dose was available, the registered weight was used to calculate the relative monthly dose.

\section{Results \\ Patient inclusion and characteristics}

From 3374 cases originally extracted from the ESID registry based on the recorded CVID diagnosis, 2700 were included in the analysis (Fig. 1). In total, 674 cases were excluded whereof 420 due to missing data on the country of residence $(n=3)$, year of CVID diagnosis $(n=254)$, follow-up period $(n=163) ; 211$ patients had no records between 2004 and 2014; 43 patients were diagnosed before the age of 4 years without any records at an older age.

The included patients originated from 23 countries, whereof 2435 (90.2\%) from Western Europe. The registration rate per million of country population varied between 0.1 (Russia) and 11.0 (Netherlands) (Fig. 2). Overall, 30.5\% were diagnosed before the age of 18 years. There was a great variability in the proportion of pediatric patients per country: from none (Lithuania) to 100\% (Poland, Russia,

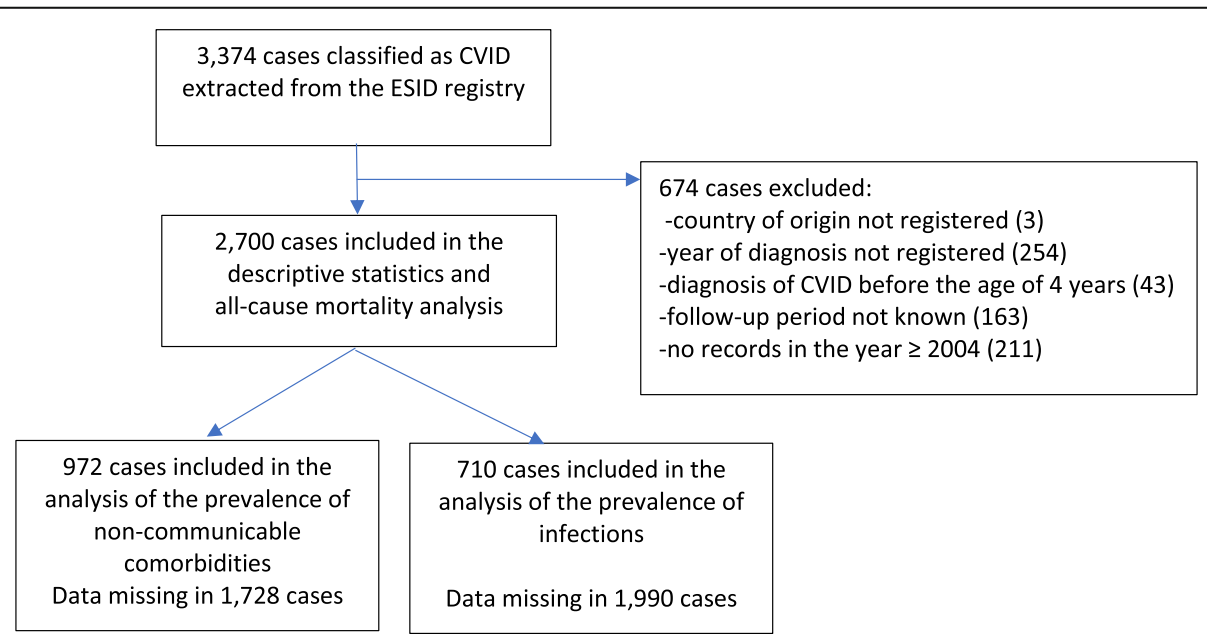

Fig. 1 Inclusion of cases in the Burden of CVID analysis 


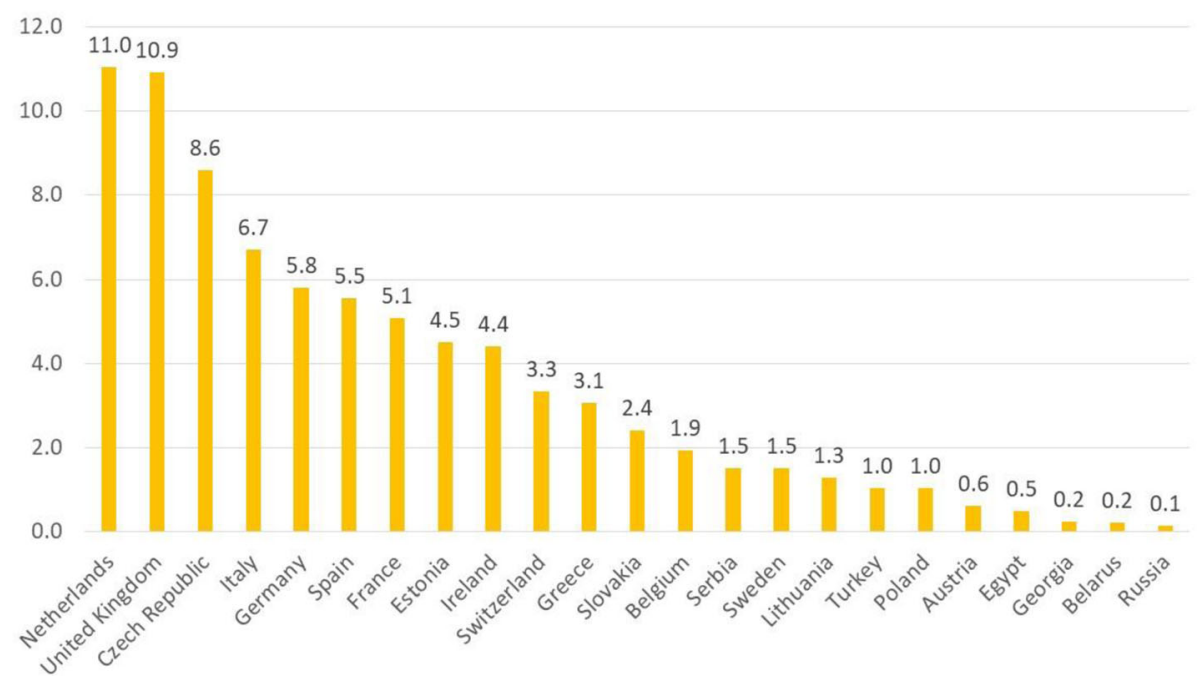

Fig. 2 Registration rate of CVID patients in the ESID registry, per 1 million by country population

Belarus, Egypt, Georgia). The total follow-up period was 24,366 person-years with a per-patient median of 6 years (Table 1).

The year of CVID diagnosis was $\leq 1980$ in $3.7 \%$; between 1981 and 1999 in 27.2\%; and $\geq 2000$ in 69.1\% of patients. The median (min; max) age at diagnosis was 31 $(4 ; 89)$ years, $26(4 ; 83)$ in males versus $34(4 ; 89)$ in females (independent samples Mann-Whitney $\mathrm{U}$ test, $p$ $<.001)$. The overall proportion of male patients was $47.9 \%$ but higher in children and lower in adults: $56.9 \%$ among those diagnosed before the age of 18 years, and $43.0 \%$ among those diagnosed as adults.

The median (min; max) age at onset of symptoms was $18(0 ; 81)$. The onset of CVID occurred at all ages, with the largest proportion (37.1\%) between 0 and 11 years. The median (min; max) diagnostic delay was 4 years $(0$; 69). The diagnosis of CVID was established in the year of disease onset in $16.0 \%$ of the patients $(n=357)$ (Table 2).

Data on parental consanguinity indicating whether the parents or other ancestors (e.g. grandparents) of the patient are genetically related, were registered in $55.1 \%$ of patients. Of these, $4.6 \%(n=68)$ were reported as offspring of consanguineous parents (Table 2).

The Ig replacement therapy was registered in $84.8 \%$ of the patients, with most of the dose records (82.4\%) listed as absolute dose. Body weight was available in $52.5 \%$ of cases. After removing erratic records of the Ig dose $(3.6 \%)$ and weight $(2.3 \%)$, the relative monthly Ig dose could be analyzed in 1567 (58.0\%) patients. The mean (SD) relative monthly dose was 454 (196) $\mathrm{mg} / \mathrm{kg}$, with a significant difference between countries $p<.0001$; the mean dose was lowest in the Czech Republic $(266 \mathrm{mg} / \mathrm{kg}$ ) and highest in Greece (544 mg/ kg) (Table 1).

\section{Mortality and years of life lost to premature death}

The all-cause mortality was analysed from the records of all included patients $(n=2700)$. Death was registered in 102 patients (3.8\%), aged between 6 and 84 years. This corresponded with 3372 Years of Life Lost due to premature death (YLLs). The annual average standardized rates per $10^{5}(95 \% \mathrm{CI})$ were $865(678 ; 1052)$ deaths and $28,013(27,009 ; 29,017)$ YLLs, exceeding the respective rates in the general population by a factor of 1.7 and 3.0. The death rates were higher than in the general population: in children aged 5 to 14 , by a factor of 38 ; in patients between 15 and 34 years of age, by a factor of 8.5 to 9 ; in those aged 35 to 54 , by a factor of 3.0 to 5.3 ; in patients aged 55 or older, by a factor of 0.6 to 1.9 (Fig. 3 and Additional file 2).

\section{Comorbidities of CVID}

Concomitant diseases and infections were registered in $972(36.0 \%)$ and $710(26.3 \%)$ patients, respectively. There was a high consistency in the ICD-10 codes and the textual diagnostic descriptions (99.9\%). The crude period prevalence rates of CVID comorbidities were largely consistent with the previously reported findings: bronchiectasis, 26.8\%; splenomegaly, $24.0 \%$; autoimmunity, 25.5\%; neoplasms, 14.1\%; enteropathy, 9.9\%; granuloma, 9.1\% (Additional file 3).

\section{Annual age-standardized prevalence of comorbidities and years of life lost to disability}

Chronic lung disease was most common, with an average annual age-standardized prevalence of bronchiectasis of 21.9\% (20.1; 23.8), asthma: 8.6\% (7.7; 9.6), COPD: $5.7 \%$ $(5.1 ; 6.3)$ and GLILD: $3.2 \%(2.5 ; 3.8)$. These prevalence rates were higher than in the general population by a 
Table 1 The number of patients, registration rate, percentage of pediatric patients, follow-up period and mean monthly lg dose per country

\begin{tabular}{|c|c|c|c|c|c|c|c|}
\hline Country & $\begin{array}{l}\text { Number of } \\
\text { patients } \\
\text { in the registry }\end{array}$ & $\begin{array}{l}\text { Rate per } 1 \text { million } \\
\text { of population }\end{array}$ & $\begin{array}{l}\text { Percentage of } \\
\text { patients diagnosed } \\
\text { before } 18 \text { y.o. }\end{array}$ & $\begin{array}{l}\text { Median (mean) } \\
\text { follow-up } \\
\text { period, years }\end{array}$ & $\begin{array}{l}\text { Total person } \\
\text { years }\end{array}$ & $\begin{array}{l}\text { Percentage of patients } \\
\text { with identified relative } \\
\text { monthly Ig dose }\end{array}$ & $\begin{array}{l}\text { Mean (SD) monthly } \\
\text { lg dose, } \mathrm{mg} / \mathrm{kg}\end{array}$ \\
\hline Austria & 5 & 0.6 & $80.0 \%$ & $9.0(10.6)$ & 53 & $80 \%$ & $450(327)$ \\
\hline Belarus & 2 & 0.2 & $100 \%$ & $3.0(3.0)$ & 6 & N.A. & N.A. \\
\hline Belgium & 21 & 1.9 & $71.4 \%$ & $6.0(7.7)$ & 162 & $61.9 \%$ & $431(110)$ \\
\hline Czech Republic & 90 & 8.6 & $30.0 \%$ & $11.0(12.1)$ & 1093 & $80 \%$ & $266(146)$ \\
\hline Egypt & 4 & 0.5 & $100 \%$ & $12.0(10.3)$ & 41 & $75 \%$ & $300(265)$ \\
\hline Estonia & 6 & 4.5 & $16.7 \%$ & $6.5(5.5)$ & 33 & $100 \%$ & $361(70)$ \\
\hline France & 319 & 5.1 & $18.8 \%$ & $6.0(10.5)$ & 3334 & $65.8 \%$ & $538(178)$ \\
\hline Georgia & 1 & 0.2 & $100 \%$ & $5.0(5.0)$ & 5 & $100 \%$ & $369(-)$ \\
\hline Germany & 475 & 5.8 & $34.5 \%$ & $7.0(9.2)$ & 4377 & $71.6 \%$ & 385 (184) \\
\hline Greece & 34 & 3.1 & $76.5 \%$ & $6.0(9.3)$ & 317 & $67.6 \%$ & $544(182)$ \\
\hline Ireland & 20 & 4.4 & $15.0 \%$ & $15.5(15.1)$ & 302 & $50 \%$ & $510(68)$ \\
\hline Italy & 397 & 6.7 & $27.7 \%$ & $7.0(8.7)$ & 3470 & $56.4 \%$ & $405(218)$ \\
\hline Lithuania & 4 & 1.3 & $0.0 \%$ & $4.0(6.5)$ & 26 & $75 \%$ & 380 (99) \\
\hline Netherlands & 183 & 11.0 & $38.3 \%$ & $8.0(9.9)$ & 1803 & $56.3 \%$ & $508(214)$ \\
\hline Poland & 39 & 1.0 & $100 \%$ & $5.0(5.6)$ & 218 & $100 \%$ & $430(142)$ \\
\hline Russia & 20 & 0.1 & $100.0 \%$ & $6.0(5.5)$ & 110 & $90 \%$ & 442 (146) \\
\hline Serbia & 11 & 1.5 & $81.8 \%$ & $4.0(5.5)$ & 60 & $90.9 \%$ & $400(0)$ \\
\hline Slovakia & 13 & 2.4 & $84.6 \%$ & $3.0(5.5)$ & 71 & $100 \%$ & 392 (156) \\
\hline Spain & 258 & 5.5 & $24.4 \%$ & $1.0(3.4)$ & 884 & $12.8 \%$ & 412 (175) \\
\hline Sweden & 14 & 1.5 & $7.1 \%$ & $8.0(10.0)$ & 140 & $78.6 \%$ & 498 (221) \\
\hline Switzerland & 26 & 3.3 & $30.8 \%$ & $7.0(7.6)$ & 197 & $69.2 \%$ & 477 (287) \\
\hline Turkey & 75 & 1.0 & $76.0 \%$ & $5.0(5.6)$ & 420 & $72 \%$ & 472 (107) \\
\hline U.K. & 683 & 10.9 & $18.9 \%$ & 7.0 (10.6) & 7244 & $52.6 \%$ & $528(165)$ \\
\hline Total/ overall & 2700 & 3.9 & $30.5 \%$ & $6.0(9.0)$ & 24,366 & $58.0 \%$ & 454 (196) \\
\hline
\end{tabular}

lg immunoglobulin, N.A. data not available, y.o. years old

factor of 65.3 in GLILD, 34.0 in bronchiectasis, and 2.2 and 1.3 for COPD and asthma, respectively (Fig. 4 and Additional file 4).

The age-standardized prevalence of autoimmune disorders was $23.2 \%$. Autoimmune cytopenias were dominated by idiopathic thrombocytopenia purpura (ITP) in $6.0 \%(5.3 ; 6.8)$ and autoimmune hemolytic anemia in $4.1 \%$ (3.7; 4.7). Overall, the prevalence of autoimmune cytopenias was 702.9 times higher than in the general population. Among the organ and systemic autoimmunities, hypothyroidism was the most prevalent type: $3.5 \%$ (3.1; 3.9), followed by alopecia areata and vitiligo: $2.7 \%$ (2.4; $2.9)$, rheumatoid arthritis: $2.4 \%(2.2 ; 2.7)$ and type 1 diabetes: $1.6 \%(1.4 ; 1.7)$. Twenty-six percent of patients had another type of autoimmunity, mostly unspecified. Compared to the general population, the overall prevalence of autoimmunity was 7.6 times higher in the CVID patients.

Digestive system disorders were annually occurring in $15.6 \%(13.9 ; 17.6)$ of patients, exceeding the prevalence rate in the general population by a factor of 8.1. Of these, $60.9 \%$ had enteropathy comprising non-infective gastroenteritis and/or colitis, coeliac disease, Crohn's disease, malabsorption and functional diarrhea.

Annual age-standardized prevalence of solid tumors was $5.5 \%(4.7 ; 6.2)$ with skin cancer being the most common type and accounting for $30.8 \%$ of all solid tumors, followed by breast cancer (12.2\%) and lung cancer $(7.5 \%)$. Gastric cancer was registered in $1.0 \%$ of the cohort over the observation period, an 8.6 times higher prevalence compared to the European population [44]. Lymphoma annually occurred in $3.8 \%(3.2 ; 4.4)$. The prevalence of lymphoma and all solid cancers exceeded the prevalence rates in the general population by a factor of 32.5 and 2.4, respectively.

The mean annual age-standardized prevalence of splenomegaly was $19.0 \%$, granuloma (other than GLILD) $4.4 \%$, and lymphoproliferation $3.9 \%$. Blood disorders (other than autoimmune cytopenias) were registered at 
Table 2 Patient characteristics

\begin{tabular}{|c|c|c|}
\hline Characteristics & $\begin{array}{l}\text { Data completeness, } \\
\mathrm{n}(\%)\end{array}$ & \\
\hline Sex, n (\%) & $2700(100 \%)$ & \\
\hline Male & & $1294(47.9)$ \\
\hline Female & & $1406(52.1)$ \\
\hline Age at diagnosis, years, & $2700(100 \%)$ & \\
\hline Median (Min; Max) & & $31.0(4 ; 89)$ \\
\hline Mean (SD) & & $31.4(19.6)$ \\
\hline \multicolumn{3}{|l|}{$N(\%)$} \\
\hline $4-10$ & & $460(17.0)$ \\
\hline $11-20$ & & $475(17.6)$ \\
\hline $21-40$ & & $939(34.8)$ \\
\hline $41-60$ & & $565(21.0)$ \\
\hline$>60$ & & $261(9.7)$ \\
\hline Age at onset, years, & $2236(82.8 \%)$ & \\
\hline Median (Min; Max) & & $18.0(0 ; 81)$ \\
\hline Mean (SD) & & $22.4(19.0)$ \\
\hline \multicolumn{3}{|l|}{ N (\%) } \\
\hline$\leq 10$ & & $829(37.1)$ \\
\hline $11-20$ & & $401(17.9)$ \\
\hline $21-40$ & & $601(26.9)$ \\
\hline $41-60$ & & $309(13.8)$ \\
\hline$>60$ & & $96(4.3)$ \\
\hline Diagnostic delay, years & $2236(82.8 \%)$ & \\
\hline Median (Min; Max) & & $4.0(0 ; 69)$ \\
\hline Mean (SD) & & $8.8(11.4)$ \\
\hline \multicolumn{3}{|l|}{$N(\%)$} \\
\hline $\begin{array}{l}0 \text { (diagnosis in the year } \\
\text { of symptoms onset) }\end{array}$ & & $357(16.0)$ \\
\hline $1-4$ & & $769(34.4)$ \\
\hline $5-9$ & & $443(19.8)$ \\
\hline $10-20$ & & $380(17.0)$ \\
\hline$\geq 21$ & & $287(12.8)$ \\
\hline Period of diagnosis, n (\%) & $2700(100 \%)$ & \\
\hline$\leq 1980$ & & $101(3.7)$ \\
\hline 1980-1999 & & $734(27.2)$ \\
\hline$\geq 2000$ & & $1865(69.1)$ \\
\hline Consanguinity, n (\%) & $1488(55.1 \%)$ & \\
\hline With consanguinity & & $68(4.6)$ \\
\hline $\begin{array}{l}\text { With records on immunoglobulin } \\
\text { replacement therapy, } \mathrm{n}(\%)\end{array}$ & $2290(84.8 \%)$ & \\
\hline
\end{tabular}

least once in $14.5 \%$ during the follow-up period, with about $50 \%$ of cases attributable to anemia and thrombocytopenia.

Serious bacterial infections (SBIs) had a much higher annual prevalence in the CVID cohort than in the general population. Pneumonia occurred in 5.6\% (4.9; $6.4)$, meningitis in $0.17 \%(0.05 ; 0.4)$ of CVID patients, exceeding the respective prevalence in the general population by factors 8.5 and 76.2 (Fig. 5). The rates of pneumonia and meningitis per person-year were 0.06 $(0.05-0.07)$ and $0.002(0.0009-0.004)$ respectively. The annual prevalence of other types of infections - lower and upper respiratory, otitis, varicella, herpes zoster, diarrhea etc. - was $34.0 \%(29.8 ; 38.7)$. The overall infection rate per person-year including SBIs was 0.4 (0.38; 0.41) (Additional file 5).

The annual age-standardized YLD rate associated with the comorbidities of CVID summed up to 8772 (6069; $12,363)$ per $10^{5}$ of this CVID cohort. Infections had the largest contribution to the disability related health loss: $32.7 \%$, followed by autoimmunity: $23.1 \%$, chronic lung diseases: $22.2 \%$, digestive system disorders: $13.7 \%$ and neoplasms: $8.2 \%$. Nearly half $(44 \%)$ of the disability burden was attributable to infections and bronchiectasis (Additional file 4).

\section{Disability adjusted life years}

The individual burden of CVID, i.e. the annual mean age-standardized DALY rate per $10^{5}$ of this cohort, was 36,785 (33,078; 41,380) (Table 3).

Accounting for the prevalence of CVID in Europe, estimated at 1 in 25,000 people $[5,6]$, the annual population health loss associated with CVID, i.e. societal disease burden, comprised $1.5(1.3 ; 1.7)$ DALYs per $10^{5}$ of the European population.

The ten leading health problems in Europe identified by the GBD caused a mean societal burden of between 187 (lower respiratory infections) and 1712 (back and neck pain) DALY per $10^{5}$ of general population [24] (Fig. 6 and Additional file 6). The burden of these diseases to the individual patient, i.e. estimated as a mean DALY rate per $10^{5}$ of population diagnosed with a respective disease, varied between 10,445 (chronic obstructive pulmonary disease); and 1,096,432 (tracheal, bronchus and lung cancers). The individual burden of CVID was somewhat below the individual burden of stroke and ischaemic heart disease: 60,247 and 52,953 DALY respectively; and considerably higher than the burden of depressive disorders, diabetes mellitus and COPD: 16,710; 12,043; and 10,445 DALY respectively (Fig. 7 and Additional file 6).

\section{Explorative analysis of the risk factors of health loss}

The overall survival rate from the year of the diagnosis was $0.95(0.93 ; 0.97)$ at 10 years, $0.76(0.71 ; 0.81)$ at 25 years, and $0.49(0.37 ; 0.66)$ at 45 years follow-up (Additional file 7). Increased mortality was associated with solid tumor, $\mathrm{HR}(95 \% \mathrm{CI}): 2.69(1.10 ; 6.57) p=$ 0.030, lymphoma: $5.48(2.36 ; 12.71) \quad p<.0001$ and 


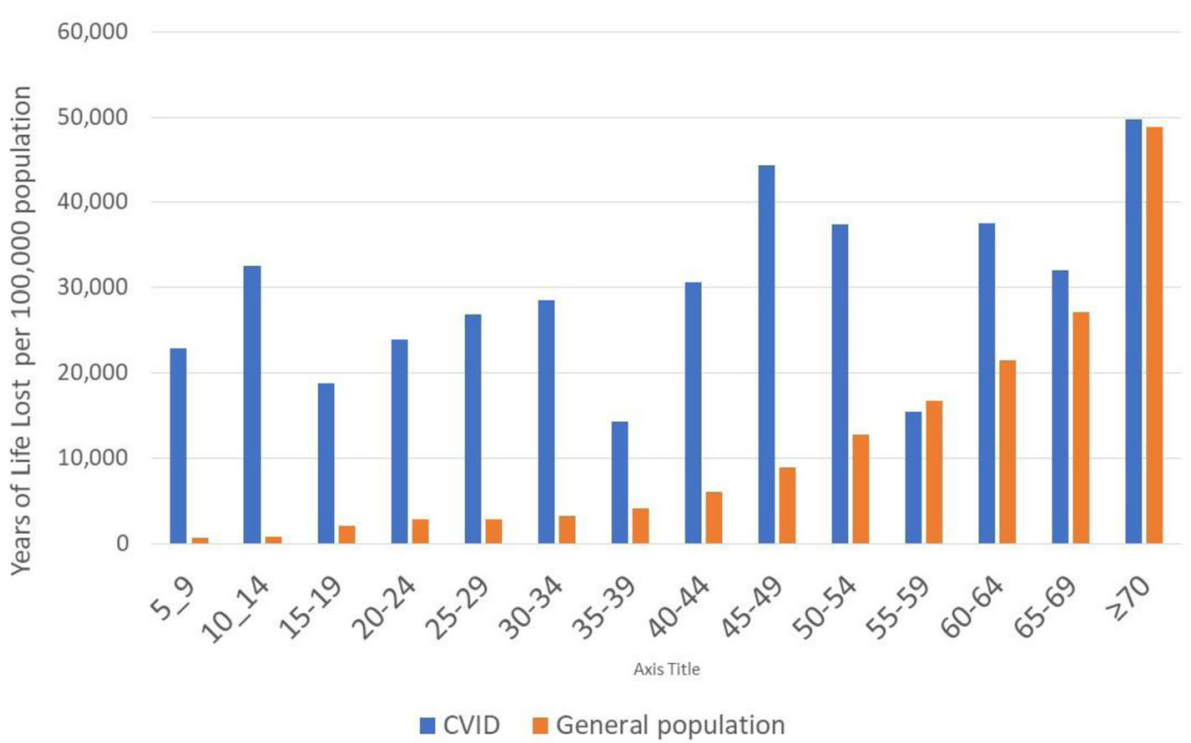

Fig. 3 Annual average rate of Years of Life Lost to premature death, per 5-year age interval, over the period: 2004-2014. CVID cohort versus general population*. All causes, both sexes. *Source: Global Burden of Disease Studies, Western Europe: http://ghdx.healthdata.org/gbd-results-tool

GLILD: 4.85 (1.63; 14.39) $p=0.005$ (Table 4). Other factors associated with increased mortality were parental consanguinity: $4.42(1.66 ; 11.75) p=.003$, higher age at symptoms onset: $1.04(1.03 ; 1.05) \mathrm{p}<.0001$, higher age at CVID diagnosis: $1.04(1.03 ; 1.05) \mathrm{p}<.0001$, and diagnostic delay adjusted for the age at symptoms onset: $1.04(1.02 ; 1.06) p=.0003$. No association between survival and sex, Ig replacement dose, or diagnostic delay adjusted for the age of the CVID diagnosis was found (Table 5).

\section{Diagnostic delay}

Diagnostic delay adjusted for the age at CVID symptoms onset was associated with the prevalence of bronchiectasis: HR $(95 \% \mathrm{CI}): 1.03(1.01 ; 1.04) p=.0001$, solid tumor: $1.08(1.04 ; 1.11) \mathrm{p}<.0001$, and enteropathy: 1.02

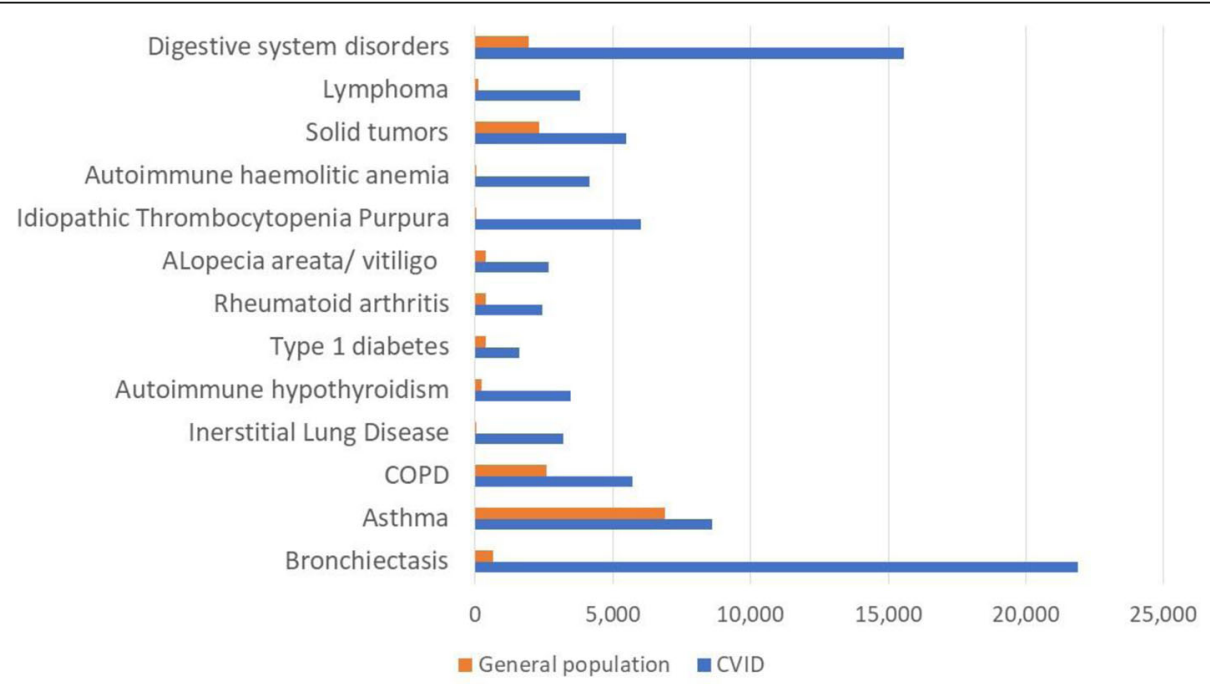

Fig. 4 Prevalence of non-communicable comorbidities. Average annual age-standardized prevalence rate per 100,000 over the period $2004-2014$. CVID cohort versus general population*. All ages, both sexes. *Source: Global Burden of Disease Studies, Western

Europe: http://ghdx.healthdata.org/gbd-results-tool 


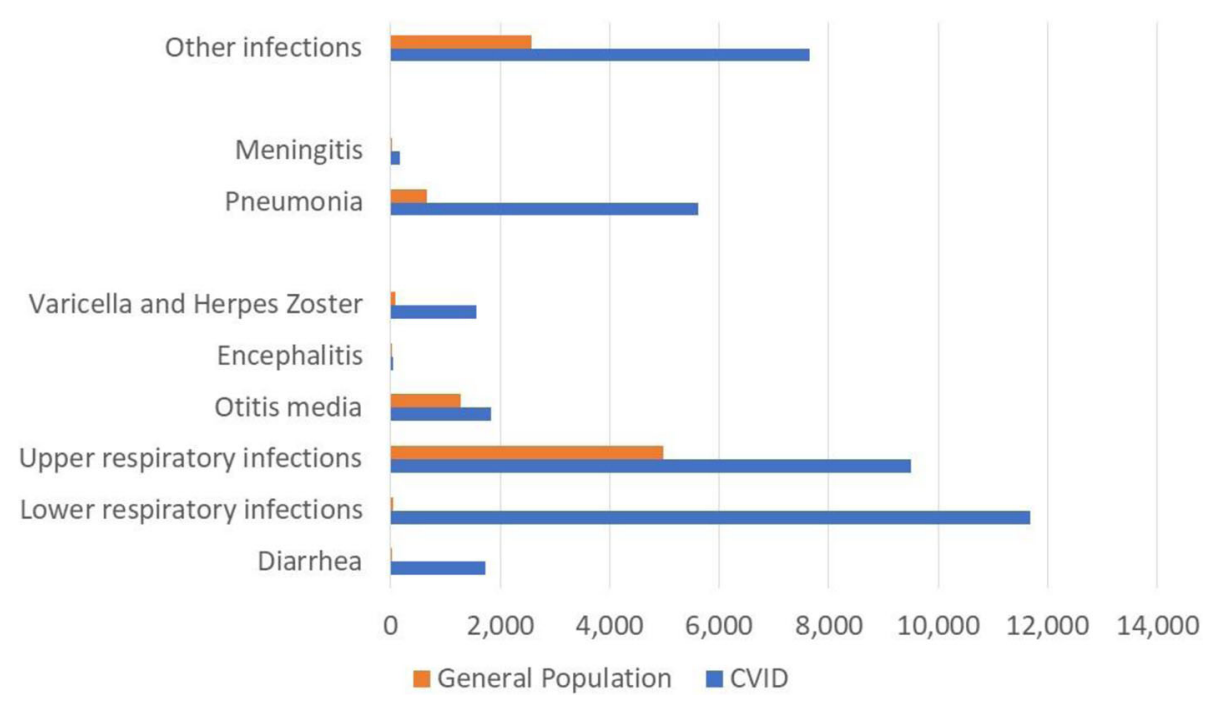

Fig. 5 Prevalence of infections. Average annual age-standardized prevalence rate per 100,000 over the period 2004-2014. CVID cohort versus general population*. All ages, both sexes. *Source: Global Burden of Disease Studies, Western Europe: http://ghdx.healthdata.org/gbd-results-tool

$(1.00 ; 1.05) p=.0447$. Diagnostic delay adjusted for the age of CVID diagnosis was associated with the prevalence of bronchiectasis only: $1.01(1.00 ; 1.03) p=0.0472$ (Table 6). A comparison of three consecutive time periods of CVID diagnosis ( $\leq 1980$; 1981-1999; and $\geq$ 2000) revealed no significant difference in diagnostic delay (independent sample Kruskal-Wallis test, $p=.228$ ) (Table 7).

\section{Discussion}

\section{Burden of disease}

The burden of more than 300 conditions worldwide has been quantified by the GBD project, however, the burden of many rare diseases remains unknown. This study presents the first estimation of the burden of CVID in Europe based on the data of the ESID registry, the largest Primary Immunodeficiency registry in the world. The annual loss of healthy life years due to premature death and living with disability was estimated between 33,078 and 41,380 per 100,000 in the CVID population and corresponded with 1.3 to 1.7 disability-adjusted life years per 100,000 in the general population in Europe.

Due to the low prevalence of CVID, the societal burden of this rare immune disorder is not comparable to that of common conditions identified by the GBD as the leading causes of health loss in Europe, such as ischemic heart disease or diabetes that annually cause a respective loss of 1125 and 389 DALY per 100,000 population in Western Europe [24]. However, the burden to the individual CVID patient is comparable with the individual burden of stroke or ischemic heart disease, and even substantially higher than the individual disease burden to patients with diabetes mellitus or COPD. In the CVID cohort, loss of healthy life years due to premature death was three times higher than in the general population. Loss of healthy life years due to comorbidities and infections was 7.3 times higher in the CVID cohort than years of life lost annually due to the same diseases in the general population.

These findings challenge the current approach to the prioritization of the healthcare problems based on the burden of a disease to the society, as rare diseases are likely to be discriminated due to their low prevalence and relatively modest impact on population health. Estimating the burden of disease to the individual patient should serve as an important additional guidance for the decisions on public health priorities and resource allocation in research and clinical care. Currently, more than 7000 rare diseases have been known affecting 30 to 40 million people in Europe, with only about $1 \%$

Table 3 Mean annual age-standardized YLLs, YLDs and DALYs over the period 2004-2014

\begin{tabular}{lll}
\hline & Mean $(95 \% \mathrm{CI})$ annual age-standardized rates per 100,000 of population \\
\hline Attribute of health loss & CVID cohort, ESID registry & General population, Western Europe \\
Years of Life Lost to death & $28,013(27,009 ; 29,017)$ & $9314(9296 ; 9332)$ \\
Years of Life Lost to disability & $8772(6069 ; 12,363)$ & $1196(751 ; 1715)$ \\
Disability-Adjusted Life Years & $36,785(33,078 ; 41,380)$ & $10,510(9998 ; 10,759)$ \\
\hline
\end{tabular}




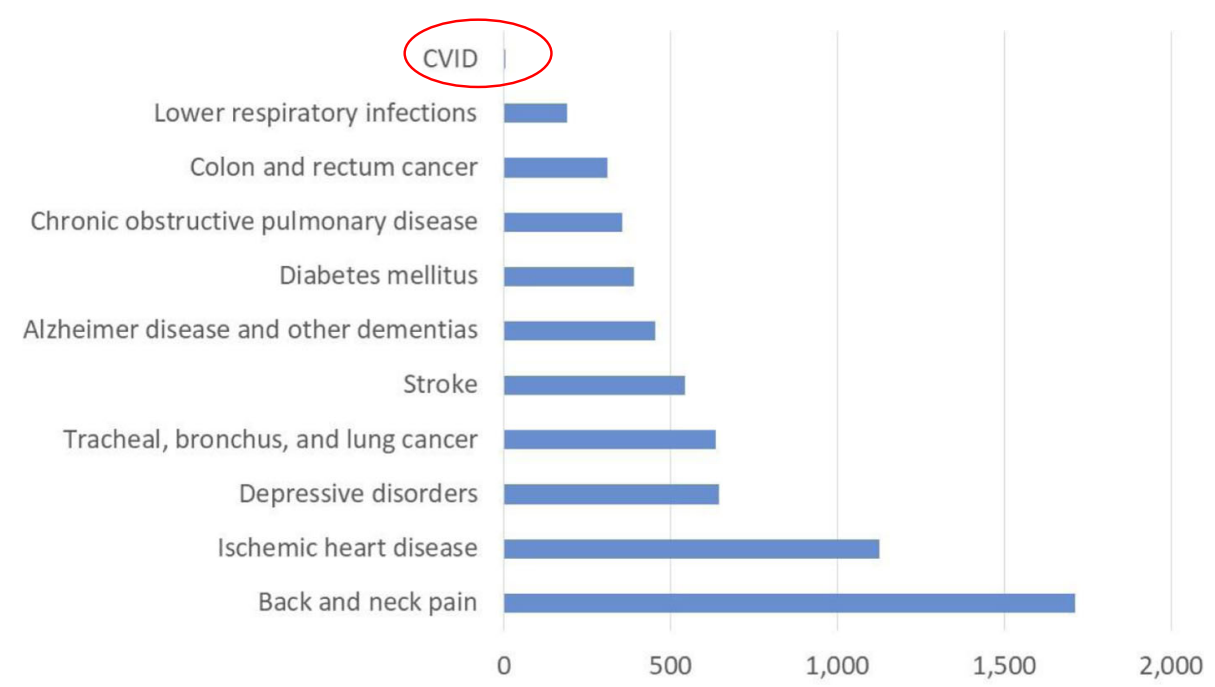

Fig. 6 Burden of disease to society: CVID versus top-ten health problems in Europe. Annual age-standardized DALY rate per 100,000 of general population*. *Source: Global Burden of Disease Studies, Western Europe 2015: http://ghdx.healthdata.org/gbd-results-tool

having an adequate treatment, while the burden of these diseases is largely unknown [28].

Poorer survival in CVID was associated with the prevalence of solid tumor, lymphoma and GLILD, showing consistency with the results of some large cohort studies [30, 45]. Our analysis of disability burden adds to this knowledge that despite the Ig replacement therapy nearly half of the total disability in the CVID cohort was attributable to infections and bronchiectasis, a frequent chronic complication of recurrent lower respiratory infections [29]. This finding emphasizes the importance of an adequate Ig replacement dosing. While no universal guidelines for an optimal Ig dose exist, current evidence suggests individualization of the Ig dose to attain infection-free outcomes [17]. In view of a relatively high prevalence of SBIs, e.g. pneumonia had a 8.5 times higher prevalence rate compared to the general population, the question occurs whether the administered Ig replacement regimens - the mean dose was overall below $500 \mathrm{mg} / \mathrm{kg}$ - were optimal for each individual patient. This study was not designed to establish a causative relationship between the drug dose and the clinical outcomes; moreover, some relevant information on potential confounders was missing, e.g. patient compliance to the therapy, or the prescribed antibiotics regimen. However, a recent meta-analysis by Orange et al. showed that the incidence of pneumonia with maintenance of $500 \mathrm{mg} / \mathrm{dL}$ IgG trough level $(0.113$

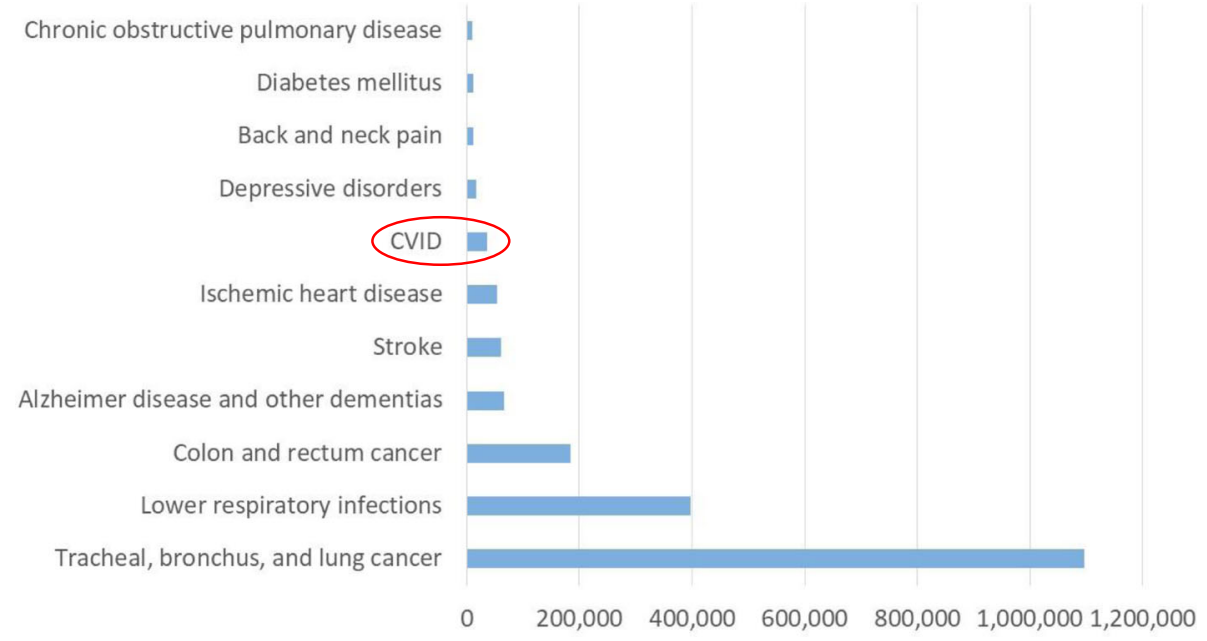

Fig. 7 Burden of disease to individual patient: CVID versus top-ten health problems in Europe. Annual age-standardized DALY rate per 100,000 of diagnosed population*. ${ }^{*}$ Calculated as DALY per 100,000 general population X 100,000/ disease prevalence per 100,000 general population 
Table 4 Association between comorbidities and all-cause mortality. Results of Cox proportional hazard model with comorbidities as time-dependent covariate $(N=972)$

\begin{tabular}{|c|c|c|c|c|}
\hline Comorbidity & $\operatorname{HR}(95 \% \mathrm{Cl})^{\mathrm{a}}$ & $P$-Value & $\mathrm{HR}(95 \% \mathrm{Cl})^{\mathrm{b}}$ & $P$-Value \\
\hline Bronchiectasis & $0.84(0.44 ; 1.62)$ & 0.612 & $0.83(0.40 ; 1.86)$ & 0.633 \\
\hline Splenomegaly & $2.11(1.17 ; 3.82)$ & 0.013 & $1.67(0.82 ; 3.39)$ & 0.155 \\
\hline Autoimmunity (organ/ systemic) & $1.61(0.79 ; 3.27)$ & 0.187 & $1.52(0.67 ; 3.43)$ & 0.311 \\
\hline Autoimmune cytopenia & $0.72(0.22 ; 2.35)$ & 0.591 & $1.08(0.33 ; 3.57)$ & 0.897 \\
\hline Enteropathy & $1.39(0.54 ; 3.56)$ & 0.493 & $0.97(0.28 ; 3.41)$ & 0.962 \\
\hline Solid tumor & $3.19(1.55 ; 6.57)$ & 0.002 & $2.69(1.10 ; 6.57)$ & 0.030 \\
\hline Lymphoma & $3.95(1.81 ; 8.66)$ & 0.001 & $5.48(2.36 ; 12.71)$ & $<.0001$ \\
\hline GLILD & $3.80(1.47 ; 9.85)$ & 0.006 & $4.85(1.63 ; 14.39)$ & 0.005 \\
\hline
\end{tabular}

anivariable analysis

badjusted for age of CVID symptoms onset

cases per patient-year) was 5 -fold that with $1000 \mathrm{mg} / \mathrm{dL}$ (0.023 cases per patient-year), declining by $27 \%$ with each $100 \mathrm{mg} / \mathrm{dL}$ increment in trough IgG level; and demonstrated a linear relationship between the trough IgG levels and the Ig dose: an increase by $121 \mathrm{mg} / \mathrm{dL}$ with each incremental increase of monthly Ig dose by $100 \mathrm{mg} / \mathrm{kg}$ [16].

The mortality rate was four times higher in patients with parental consanguinity, suggesting unidentified autosomal recessive disease underlying the CVID-classification in these patients. Parental consanguinity was previously reported as a predictor of death in PID [37-40]. Higher age at symptoms onset and higher age at CVID diagnosis were associated with poorer survival chances, a confirmation of previous findings [11, 30, 31]. We also explored diagnostic delay in a bivariable survival analysis, first in conjunction with the age at diagnosis, then with the age at symptoms onset. The first analysis shows whether/ how diagnostic delay affects survival in CVID patients diagnosed at the same age, the second - how it affects those

Table 5 Results of an explorative survival risk factor analysis. Results are obtained with Cox proportional hazards model ( $N=$ 2700)

\begin{tabular}{lll}
\hline Risk factor & HR: Mean $(95 \% \mathrm{Cl})$ & $P$ value \\
\hline Age at diagnosis $^{\mathrm{a}}$ & $1.04(1.03 ; 1.05)$ & $<.0001$ \\
Age at symptoms onset $^{\mathrm{a}}$ & $1.04(1.03,1.05)$ & $<.0001$ \\
Sex $^{\text {ffemale })^{\mathrm{a}}}$ & $1.14(0.77 ; 1.69)$ & 0.515 \\
Age at diagnosis $^{\mathrm{b}}$ & $1.05(1.04-1.06)$ & $<.0001$ \\
Age at symptoms onset $^{\mathrm{b}}$ & $1.05(1.04-1.06)$ & $<.0001$ \\
Consanguinity $^{\mathrm{c}}$ & $4.42(1.66 ; 11.75)$ & 0.003 \\
Monthly lg dose $^{\mathrm{c}}$ & $1.00(0.99 ; 1.00)$ & 0.780 \\
Diagnostic delay $^{\mathrm{d}}$ & $0.99(0.97-1.01)$ & 0.221 \\
Diagnostic delay $^{\mathrm{e}}$ & $1.04(1.02 ; 1.06)$ & 0.0003 \\
\hline
\end{tabular}

${ }^{a}$ resuls of a univariable analysis

${ }^{\mathrm{b}}$ results adjusted for diagnostic delay

cresults stratified for the age at CVID diagnosis and sex

${ }^{d}$ results adjusted for the age at CVID diagnosis

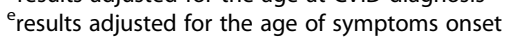

patients who experienced the symptoms onset at the same age. Our analysis has shown that diagnostic delay - when accounting for the age at symptoms onset - is a predictor of mortality and comorbidities. Each year of increase in diagnostic delay was associated with an increase of the risk of death by $4 \%$, bronchiectasis by $3 \%$, solid tumor by $8 \%$ and enteropathy by $2 \%$. Adjusting for the age of symptoms onset rather than for the age of diagnosis may be clinically more relevant as diagnostic delay of several years is frequent and rather reflects the healthcare system (in)efficiency rather than the clinical marker of the disease. These findings are hypothesis generating and need to be confirmed in prospective studies. A diagnostic delay of $\geq 1$ (up to 69!) years was found in $84 \%$ of the cohort and therefore represents a major concern, especially in view of our finding that the length of this delay has not decreased over a period of decades, despite the efforts of the primary immunodeficiency (PID) community to facilitate timely diagnosis of immunodeficiencies e.g. through a system of warning signs and educational activities. An effective algorithm based on the use of electronic patient health records to support non-expert primary and secondary care physicians to identify potential PID is not yet available and has to be developed with high priority [32-35]. It's been estimated that the treatment cost of undiagnosed PID patients in the U.S was 5 times higher than of those diagnosed and receiving Ig replacement therapy [36]. Introducing tools supporting early recognition of potential CVID could deliver a high return on investment.

\section{Limitations of the study}

Comorbidities and infections were registered in 36.0 and $26.3 \%$ of patients respectively; and our prevalence estimation was based on these subsets. To address the uncertainty associated with the quality of the registry data, the results were compared with previously published findings. The survival rate as well as the period prevalence of comorbidities and SBIs were consistent with those reported elsewhere [2, 3, 6, 14-16, 29-31, 41-43]. 
Table 6 Association between diagnostic delay and the prevalence of comorbidities in the CVID cohort. Results of proportional Cox regression $(N=972)$

\begin{tabular}{|c|c|c|c|c|}
\hline \multirow[t]{2}{*}{ Comorbidities } & \multicolumn{4}{|l|}{ HR: Mean $(95 \% \mathrm{Cl})$} \\
\hline & $\begin{array}{l}\text { Results adjusted for the } \\
\text { age at CVID diagnosis }\end{array}$ & $P$ value & $\begin{array}{l}\text { Results adjusted for the } \\
\text { age at symptoms onset }\end{array}$ & $P$ value \\
\hline Bronchiectasis & $1.01(1.00 ; 1.03)$ & 0.0472 & $1.03(1.01 ; 1.04)$ & 0.0001 \\
\hline Solid tumor & $1.01(0.99 ; 1.04)$ & 0.2604 & $1.08(1.04 ; 1.11)$ & $<0.0001$ \\
\hline Lymphoma & $0.96(0.91 ; 1.02)$ & 0.1919 & $0.98(0.93 ; 1.04)$ & 0.5713 \\
\hline Splenomegaly & $1.00(0.98 ; 1.02)$ & 0.9053 & $1.00(0.98 ; 1.02)$ & 0.9611 \\
\hline Chronic lung disease (COPD, asthma) & $0.98(0.96 ; 1.01)$ & 0.2543 & $0.99(0.96 ; 1.02)$ & 0.4545 \\
\hline Autoimmunity (organ, systemic) & $1.00(0.98 ; 1.03)$ & 0.9725 & $1.00(0.98 ; 1.03)$ & 0.6958 \\
\hline Enteropathy & $1.02(1.00 ; 1.04)$ & 0.1206 & $1.02(1.00 ; 1.05)$ & 0.0447 \\
\hline Autoimmune cytopenia & $0.97(0.92 ; 1.02)$ & 0.1973 & $0.96(0.91 ; 1.01)$ & 0.0892 \\
\hline GLILD & $0.90(0.80 ; 1.01)$ & 0.0771 & $0.91(0.80 ; 1.02)$ & 0.1045 \\
\hline Granuloma (other than GLILD) & $0.98(0.92 ; 1.03)$ & 0.3726 & $0.97(0.92 ; 1.03)$ & 0.3362 \\
\hline Lymphoproliferation & $0.98(0.93 ; 1.03)$ & 0.4132 & $0.99(0.94 ; 1.04)$ & 0.6758 \\
\hline
\end{tabular}

However, the prevalence of infections, particularly other than SBIs, was probably underreported, as the overall infection rate of 0.4 per person-year was lower than that reported by Lucas et al. and by Berger in patients treated with immunoglobulin: a rate of 2.16 and 2.8 to 5.2 per person-year respectively $[15,42]$. Walsh and colleagues observed a decline from a median of 2.0 infections per pretreatment year to 0.4 infections per year posttreatment, referring to sinopulmonary infections only [43]. This assumed underreporting of infections may have caused underestimation of the true disability associated with infections in CVID.

For the estimation of years lost to disability, we used the results of the GBD study for YLDs in the general population, adopting the assumption that the severity distribution in CVID patients would be comparable with that observed in the general population. A lack of definition and quantification of the burden of some CVID comorbidities in the scientific literature, such as unspecified autoimmunity and certain blood disorders, may have led to additional underestimation of the total CVID disability. A structural and uniform collection of the self-perceived health status in patients with CVID would help to better determine the burden for CVID patients with different clinical phenotypes and has been introduced by individual centers $[46,47]$.

Table 7 Diagnostic delay per period of diagnosis (years)

\begin{tabular}{llll}
\hline Period of diagnosis & Mean 95\% Cl & Median & Range \\
\hline$\leq 1980$ & $7.4(5.1 ; 9.8)$ & 3.5 & $0-44$ \\
$1981-1999$ & $8.6(7.7 ; 9.5)$ & 4.0 & $0-65$ \\
$\geq 2000$ & $8.8(8.2 ; 9.3)$ & 4.0 & $0-69$ \\
\hline
\end{tabular}

A division of the cohort in clinically relevant subsets for the purpose of a comparative burden of disease analysis was not feasible in this study, since results of genetic tests and the available immunological measurements, such as T-lymphocytes counts, were too limited in terms of their quantity and/or quality. The observed high mortality in children, and the reported cases of parental consanguinity are in general not typical for CVID and may indicate that patients with Combined Immunodeficiency might have been classified as CVID in some cases [48-50].

The records of the ESID registry used in this study are not necessarily representative for the national clinical practices in Europe, as a positive self-selection of the contributing treatment centers is possible, resting on the individual commitment of a select group of clinical immunologists. Furthermore, there was a strong variation in the number of patients and the registration rate per country, inhibiting a meaningful between-country comparison. A further specification of the burden of CVID per country is warranted based on the national primary immunodeficiency registries.

As previously discussed, at the moment, different centres classify patients in different ways: some only accept a diagnosis of CVID in case both IgG and IgA are low, others consider decreased IgG and IgM also sufficient. Also, many hypogammaglobulinemic patients who do not fully meet the diagnostic criteria for CVID show a severe course with infections and bronchiectasis. A regular repetition of burden of disease studies based on a more extended datasets containing genetic and immunolaboratory tests is recommended, to further identify pheno- and genotypes responsible for a higher morbidity and mortality, to track the evolution of care standards and clinical outcomes over time and to compare the 
results of the healthcare systems in different regions of the world.

\section{Conclusion}

The rates of mortality and serious comorbidities of people with CVID drastically exceed the respective rates in the general population, imposing a high disease burden to the individual patient. Our study demonstrates the need to advance timely diagnosis and treatment of CVID, to achieve improved clinical outcomes and reduce the burden of disease. The importance of a consistent and uniform data registration on PID patients in Europe, to improve understanding of these rare heterogeneous diseases, cannot be overemphasized.

\section{Endnotes}

${ }^{1}$ Today, there is no complete consensus regarding the definition of CVID. The discussion particularly concerns the presence of a decreased IgA level as an imperative diagnostic criterion. While ESID recommends diagnosis of CVID based on a marked decrease of IgG and a marked decrease of IgA (with or without low IgM levels; 2014), the international consensus "ICON" (2016) suggests less stringent diagnostic criteria: a marked decrease of IgG and at least one of IgM or IgA (3,7, Additional file 8). Patient inclusion was based solely on the diagnosis by their immunologists and not verified according to the diagnostic criteria due to limitations of the dataset.

\section{Additional files}

Additional file 1: Overview of the ESID registry data used in this study. (DOCX $14 \mathrm{~kb}$ )

Additional file 2: Table: Rates of death and Years of Life Lost to all-cause mortality in the CVID cohort and the general population, per 5-year age interval. (DOCX $17 \mathrm{~kb}$ )

Additional file 3: Table: Prevalence rates of CVID comorbidities. (DOCX $15 \mathrm{~kb})$

Additional file 4: Table: Age standardized rate of prevalence of comorbidities and Years Lost to Disability in the CVID cohort and the general population. (DOCX $27 \mathrm{~kb}$ )

Additional file 5: Table: Infection rates in the CVID cohort. (DOCX 22 $\mathrm{kb})$

Additional file 6: Burden of disease to society and the individual patient. (DOCX $15 \mathrm{~kb}$ )

Additional file 7: All-cause mortality table, CVID cohort. (DOCX $16 \mathrm{~kb}$ )

Additional file 8: Diagnostic criteria of CVID. (DOCX $15 \mathrm{~kb}$ )

\section{Abbreviations}

Cl: Confidence interval; COPD: Chronic obstructive pulmonary disease; CVID: Common variable immunodeficiency disorders; DALY: Disability adjusted life years; ESID: European Society for Immunodeficiencies; GBD: Global burden of disease study; GLILD: granulomatous-lymphocytic interstitial lung disease; HR: Hazard ratio; ICD-10: International classification of diseases; ITP: Idiopathic thrombocytopenia purpura; PPTA: Plasma Protein Therapeutics Association; SBIs: Serious bacterial infections; WHO: World Health Organization; YLD: Years lost to disability; YLL: Years of life lost to premature death

\section{Acknowledgements}

We thank the immunology treatment centers who contributed to the development of the ESID registry: Uwe Wintergerst, Markus Seidel, D. Haninger, Agnes Gamper, Wolfgang Schwinger, Andreas Klein-Franke, Regina Jones, Kambis Sadeghi, Gabriele Kropshofer, Christian Huemer, Michael Sohm, Andreas Heitger, Elisabeth Förster-Waldl, Rosmarie Dengg, Christiane Höllinger, Georg Ebetsberger-Dachs, Barbara Jauk, Martina Winkler, Daniela Ambrosch-Barsoumian, Vienna, Austrian PID Network (AGPI), Austria; Olga Aleinikova, Svetlana Aleshkevich, Svetlana Sharapova, Minsk, Belarusian Research Center for Pediatric Oncology and Hematology, Belarus; Claire-Michele Farber, Bruxelles, National Registry, Unite de Traitment des Immunodeficiences; Filomeen Haerynck, Frans de Baets, Victoria Bordon, Maite Dewerchin, Gent, Centre for Primary Immune Deficiencies, University Hospital Gent; Isabelle Meyts, Christiane De Boeck, Marijke Proesmans, François Vermeulen, Refiloe Masekela, Jacqui van Rens, Diane Delaplace, Leuven, UZ; Pierre Philippet, Subcenter Clinique de l'Espérance Montegnée; Alice Ferster, Subcenter HUDERF Bruxelles; Claire Hoyoux, Subcenter La Citadelle Université de Liège; Christophe Chantrain, Christiane Vermylen, Subcenter UCL St Luc; Wim Stevens, Subcenter UZA Antwerp; Iris de Schutter, Sophie Bravo, Anne Malfroot, Subcenter VUB Brussels, Belgium; Alessandro Plebani, Annarosa Soresina, Concetta Forino, Vassilios Lougaris, Fulvio Porta, Brescia, Dept. Pediatrics Italy, Jiri Litzman, Jindrich Lokaj, Vojtech Thon, Eva Hlaváčková Brno, Masaryk University, St.Anne Univ. Hosp. (National Centre); Aleksandra Uszynska, Subcenter Wroclaw; Edyta Jargulinska, Subcenter Wroclaw; Anna Sediva, Subcentre Prague, University Hospital Motol; Olga Krystufkova, Subcentre Prague, Rheumatology, Czech Republic; Shereen Reda, Cairo, Ain Shams University; Aisha Marsafy, Nermeen Mouftah, Galal Jeannet Botros, Cairo University, Dept. of Pediatrics, Primary Immunodeficiency Clinic, Centre for social and preventive medicine (CSPM), Egypt; Sirje Velbri, Tallinn, Children's Hospital, Estonia; Anne Durandy, Alain Fischer, Paul Landais, Romain Micol, Yasmine Dudoit, Lilia Ben Slama, Capucine Picard, Marianne Debré, Eric Oksenhendler, Olivier Lortholary, Olivier Hermine, Dominique Stoppa-Lyonnet, Thamila Berdous-Samed, Loic Le Mignot, Agathe Roubertie, Francois Rivier, Julien Beauté, Yasmina Messaoud, Abla Akl, Noemie Guibert, Sophie Hilpert, Nathalie De Vergnes, Gaelle Obenga, Pauline Brosselin, Chantal Andriamanga, Laurence Costes, Cécile Lafoix-Mignot, Virginie Courteille, Amélie Bigorgne, Carolina Brito de Azevedo Amaral, Paris, CEREDIH, Hopital Necker Enfants Malades, France; Moritz Muschaweck, Aachen, Klinik für Kinder- und Jugendmedizin; Ulf Müller-Ladner, Walter Hermann, Bad Nauheim, KerckhoffKlinik: Rheumatologie und Klinische Immunologie; Volker Wahn, Dietke Buck, Horst von Bernuth, Barbara Wolf, Herbert Steffin, Renate Krüger, Cornelia Feiterna-Sperling, Berlin, Charité - Ambulanz Infektionsimmunologie; Leif G. Hanitsch, Carmen Scheibenbogen, Yüksel Vural, Carolin Giannini, Uwe Kölsch, Berlin, Charité - Institut für Med. Immunologie, Immundefekt Ambulanz für EW; Barbara Selle, Nadja Rieckehr, Claudia Schulz, Henriette Haenicke, Lutz Wickmann, Lothar Schweigerer, Berlin-Buch, Helios: nkologie/Hämatologie; Uwe Schauer, Tobias Rothoeft, Veronika Baumeister, Bochum, Universitäts Kinderklinik; Jürgen K. Rockstroh, Brigitta Becker, Karina Mohrmann, Angelika Engelhardt, Carolynne Schwarze-Zander, Jan-Christian Wasmuth, Evrim Anadol, Christoph Boesecke, Bonn, Immunologische Ambulanz (auf dem Berg); Dagmar Dilloo, Martina Zimmermann, Brigitte Hülsmann, Olga Moser, Stefan Schönberger, Roswitha Blume, Petra Prämassing-Scherzer, Bonn, Universitätsklinikum, Pädiatrische Hämatologie und Onkologie (K); Petra KaiserLabusch, Hans-lko Huppertz, Martina Bührlen, Wolfgang Marg, Bremen, Prof.Hess-Kinderklinik; Bernhard Schaaf, Dominik T. Schneider, Michael Heike, Karin Henrichs, Marion Riedel Dortmund, Klinikum Dortmund gGmbH; Joachim Roesler; Angela Rösen-Wolff, Manfred Gahr, Jana Möller, Ramona Girrbach, Andrea Näke, Anne-Rose, Klaus-Zetzsche, Christiane Müller, Dresden, Universitätsklinikum Carl Gustav Carus, Klinik und Poliklinik für Kinder- und Jugendmedizin Pädiatrie; Andrea Kündgen; Anna Papatriantafillou-Schmieder, Tobias Strapatsas, Düsseldorf, Innere Medizin; Oliver Feyen, Sven Bellert, Arndt Borkhardt, Kirsten Bienemann, Monika Schmitz, Petra Lankisch, Andrea Hönscheid, Petra Lesch, Düsseldorf, Uni-Kinderklinik; Klaus-Daniel Stachel, Thorsten Langer, Bettina Sobik, Erlangen, Kinder- und Jugendklinik (Uniklinik); Thomas Harrer, Erlangen, Medizinische Klinik 3 - Immunologie, Rheumatologie (Uniklinik); Christof Specker, Martina Linßner, Miriam Mutert, Lisa Laubenthal, Monika Warneke, Essen, Klinik für Rheumatologie und Klinische Immunologie, Zentrum für Innere Medizin der Kliniken Essen Süd; Hans-Joachim, Büttner Flonheim: Kinder- und Jugendarztpraxis Dr. med. Büttner; Harald Burkhardt, Matthias Wahle, Frankfurt, Rheumatologische Ambulanz, Med. Klinik Il; Christoph 
Königs, Stefan Zielen, Ralf Schubert, Hermann Stimm, Richard Linde, Sandra Voß, Martin Christmann, Katerina Barfusz, Bianca Reimers, Kai Beuckmann, Inmaculada Martinez-Saguer, Emel Aygören-Pürsün, Wolfhart Kreuz, Maiken Skarke, Peter Bader, Birgit Gülnur, Ari-Arslan, Christina Schäfe, Christina Hoffmann, Aileen Bücker, Helena Pommerening, Chantal Hintze, Frankfurt, University Hospital; Klaus Warnatz, Judith Deimel, Barbara Frisch, Sigune Goldacker, Julia Horn, Manuella Gomes, Marion Klima, Sabine M. El-Helou, Simone Schruhl, Philipp Henneke, Beate Roller, Freiburg, Immunology; llka Schulze, Carsten Speckmann, Henrike Ritterbusch, Doris Löw, Roland Elling, Freiburg, Children's hospital; Christof Kramm, Silke Kullmann, Anja Hernández, Angela Hübner, Mandy Dähling, Cornelia Reinhardt, Göttingen, Unimedizin: Zentrum Kinderheilkunde und Jugendmedizin; Roswitha Bruns Greifswald, Klinik und Poliklinik für Kinder und Jugendmedizin; Dieter Körholz, Thomas Müller, Tamara Reiß, Matthias Girndt, Alexander Kühn, Melanie Winkler, Stefanie Faustmann, Halle, Poliklinik für Kinder- und Jugendmedizin (Uniklinik); Allan Brolund, Kurt Ullrich, Sarah Müller-Stöver, Marijke Sornsakrin, Robin Kobbe, Hamburg, Uniklinik Hamburg-Eppendorf: Immundefekt-Ambulanz; Ingo Müller, Birgit Garwer, Johanna Schrum, Reinhard Schneppenheim, Kai Lehmberg, Elisabeth Weißbarth-Riedel, Daniela Nolkemper, Hamburg-Eppendorf, Uniklinik: Pädiatrische Hämatologie und Onkologie, Hamburger Arbeitsgemeinschaft Angeborene Immundefekte, Torsten Witte, Hannover, Immunology; Reinhold Ernst Schmidt, Matthias Stoll, Gesine Schürmann, Björn Meyer, Dirk Meyer-Olson, Diana Ernst, Daniel Vagedes, Gudrun Mielke, Sabine Maaß, Faranaz Atschekzei, Elvira Schürmann, Hannover, Immunology; Ulrich Baumann, Anna-Maria Dittrich, Dorothee Viemann, Marzena Schaefer, Christian Hennig, Hannover, Pneumology; Johann Greil, Andreas Kulozik, Donate Jakoby, Claudia Blattmann, Jutta Mattern, Mutlu Kartal-Kaess, Heidelberg, Kinderklinik III, Immunologie, Uniklinik; Michael Pfreundschuh, Homburg, Innere Medizin; Arne Simon, Norbert Graf, Sabine Heine, Elisabeth Friedel, Homburg: Uniklinik für Pädiatrische Onkologie und Hämatologie; Tobias Ankermann, Philipp von Bismarck, Angelika Dombrowski, Kiel, UKSH Campus Kiel, Allgemeine Pädiatrie; Rainald Zeuner, Stefan Schreiber, Kiel, UKSH: Innere Medizin I; Stephan Weidinger, Kiel, UKSH: Hautklinik; Michael Weiß, Monika Streiter, Beate Tönnes, Sonja Higgins, Dagmar Freitag, Sebastian Poulheim, Köln, Kinderkrankenhaus Amsterdamer Straße (Riehl); Michael Hallek, Kai Hübel, Gerd Fätkenheuer, Köln, Klinik I für Innere Medizin; Manfred Weber, Köln Krankenhaus Merheim, Med. Klinik 1; Tim Niehues, Kathrin Siepermann, Gregor Dückers, Christian Heinrich, Monika Wicher, Heike Wachuga, Lalash Abrahim, Christian Becker, Verena Nemitz, Stefanie Esper, Tariq Lodin, Ruy Perez-Becker Krefeld ID Cente; Michael Borte, Maria Faßhauer, Grit Brodt, Antje Werner, Daniela Goebel, Stephan Borte, Anett Uelzen, Elisabeth Gnodtke, Volker Schuster, Corinna Gebauer, Arndt Bigl, Leipzig, University Children's hospital; Dagmar Graf, Leipzig, MVZ Dr. Reising-Ackermann und Kollegen; Volker Aumann, Norbert Beck, Magdeburg, Unikinderklinik; Wilma Mannhardt-Laakmann, Martina Kirchner, Fred Zepp, Sabine Wiegert, Anja Sonnenschein, Mainz, Klinikum der Johannes-Gutenberg-Universität Mainz, Univ-Kinderklinik; Andreas Neubauer, Marburg Uniklinik, Klinik für Innere Medizin, Schwerpunkt Hämatologie, Onkologie und Immunologie; Carla Neumann, München, LMU, Med. Poliklinik: AIDA - Adulte ImmunDefekt Ambulanz; Uta Behrends, Stefan Burdach, Alexandra Desta, Angela Wawer, München TU Kinderklinik; Bernd H. Belohradsky, Engelhorn Gundula Notheis, Kristina Huß, Eleonore Renner, Christoph Klein, Franz Sollinger, Gaby Strotmann, Simon Leutner, Klein Michael Albert, Annette Jansson, Silvia Stojanov, Eva Eisl, Simon Urschel, Anita Rack, Valerie Heinz, Christina Wolschner, Renate Bancé, Steffi Schlieben, Regina Steck, Petra Manzey, Naschla Kohistani, Najla Assam, Fabian Hauck, Lydia Wiesböck, Sebastian Hesse, München, Children's Hospital Dr. von Hauner, LMU; Johannes Bogner, München, LMU, Infektionsabteilung; Johannes Roth, Dirk Föll, Martina Ahlmann, Katja Masjosthusmann, Helmut Wittkowski, Heymut Omran, Elisabeth Rolfes, Antje Hellige, Münster, University Children's hospital; Michael Kabesch, Regensburg - Uniklinik oder Krankenhaus Barmherzige Brüder; Marcus Jakob, Selim Corbacioglu, Regensburg, Uniklinik, Klinik und Poliklinik für Kinder- und Jugendmedizin; Carl Friedrich Classen, Jessica Klasen, Rostock, University Childrens Hospital; Gerd Horneff, Friedrich Herrmann, Daniela Popihn, Thilo Schmalbach, Tilman Geikowski, Sigrid Fitter, Monika Szemkus, Monique Wiehe, Ria Kümmler, Ariane Klein, Simone Kiwit, Sankt Augustin, Asklepios Klinik Sankt Augustin; Stefan Bielack, Katrin Apel, Ute Groß-Wieltsch, Katja Simon-Klingenstein, Stuttgart, Klinikum Stuttgart Olgahospital, Pädiatrie, Onkologie, Hämatologie und Immunologie; Nikolaus Peter Rieber, Rupert Handgretinger, Michaela Döring, Christel Winkler, Tobias Feuchtinger, Tübingen, Universitätsklinikum für Kinder- und Jugendmedizin; Lothar Kanz, Jörg Henes, Nicole Ristl, Heidi Riescher, Martin Faber, Ina Kötter, Christina Buchta, Tanja Hüttner-Foehlisch, Hans Leibfrit, Tübingen, Med. Uniklinik
(Rheuma); Wilhelm Friedrich, Ansgar Schulz, Klaus Schwarz, Sandra Steinmann, Manfred Hönig, Annelie Lubatschofski, Karin Andritschke, Ulm, University Children's Hospital; Henner Morbach, Johannes G. Liese, Hans-Peter Tony, Carmen Müglich, Stefan Kleinert, Tanja Ritz, Yvonne Kochler, Florian Segerer, Martina Prelog, Tobias Schwarz, Gabriele Haase, Sebastian Schuh, Dagmar Blank, Helga Taschner, Marina Popp, Beate Winkler, Antari Vasiliki, Martin Herbst, Denise Yilmaz, Eva Scharbatke, Würzburg, Universitätsklinikum, Zentrum für Innere Medizin (ZIM), Pädiatrische Infektiologie und Immunologie, Germany; Maria Kanariou, Manolis Liatsis, Maria Ktistaki, Sofia Tantou, Athens, Aghia Sophia Children's Hospital; Maria Hatzistilianou, Thessaloniki Immunology Laboratory, Aristotle University, Efimia Papadopoulou-Alataki Thessaloniki, General Regional Hospital Papageorgiou, Aristotle Univ:; Maria Trachana, Evangelia Farmaki, Thessaloniki, Ippokration General Hospital, Greece; Conleth Feighery, Dublin, St. James's Hospital, Ireland; Roberto Rondelli, AIEOP (Associazione Italiana Ematologia Oncologia Pediatrica); Eleonora Gambineri, Clementina Canessa, Florence, University of F, Dep. Pediatrics; Anna Villa, Maria Cristina, Pietrogrande, Milano, ITB, Segrate; Claudio Pignata, Naples, Pediatrics, Italy; Audra Blaziene, Vilnius Santariskiu Klinikos University Hospital, Center of Pulmonology and Allergology; Rasa Duobiene, Vilnius University Children's Hospital, Lithuania; Corrie MR Weemaes, Taco W. Kuijpers, Jaap-Jan Boelens, Merlijn van den Berg, Chris Nieuwhof, J.M. van Montfrans, Adilia Warris, Marc Bijl, G.J.A. Driessen, P.M. Ellerbroek, Sadia Hussain, Ilona Kleine, Budde Adya Noorlander, E.H. Schölvinck, RJM ten Berge, Rachel T van Beem, J.T. van Dissel, P.M. van Hagen, Geoffrey van Ogtrop, G.Th.J. van Well, Anna Simon, Josine de Witte, M.M. den Os, H.Anne Grashoff, Margje H. Haverkamp, Maartje Eekman, Ellen Schatorje, Ruben Meijer, Pearl Mau-Asam, Birgit Jonkman-Berk, Michiel van der Flier, Riet Strik-Albers, Hanna ljspeert, Amsterdam, National Dutch Registry Emma Children's Hospital, Academic Medical Center (AMC), Division of Pediatric Hematology, Immunology and Infectious diseases; Annet van Royen-Kerkhof, Wietse Kuis, NM Wulffraat; Kim Albers, Utrecht, University Medic Center, Netherlands; Anna Macura-Biegun, Anna Szaflarska, Krakow, Jagiellonian University Medical Collage, Bozena Micoloc, Radoslaw Motkowski, Subcenter Bialystok; Sylvia Koltan, Subcenter Bydgoszcz; Ninela Irga, Subcenter, Gdansk; Jarek Pasnik, Subcenter Lodz; Aleksandra Poplonek, Subcenter Poznan; Ewa Bernatowska, Barbara Pietrucha, Beata Wolska-Kusnierz, Malgorzata Pac, Maja Klaudel-Dreszler, Magdalena Kurenko - Deptuch, Edyta Heropolitanska, Krystyna Chrzanowska, Warsaw, Children's Memorial Health Institute, Poland; Julia Konoplyannikova, Anna Shcherbina, Moscow, Federal Research and Clinical Center for Pediatric Hematology, Oncology, Immunology; Irina Kondratenko, Olga Paschenko, N.N. Vaganov, Moscow, Russian State Children's Hospital; Marina Guseva, Saint Petersburg, Pasteur Institute, Russia; Srdjan Pasic, Belgrade, Mother and Child Health Institute, Serbia; Peter Ciznar, Hana Kayserova, Linda Libai Véghová, Bratislawa, Children's University Hospital; Milos Jesenak Martin, Centre for Immunopathological Conditions, Slovakia; Laia Alsina, Manrique de Lara, Barcelona, Hospital Sant Joan de Deu; Javier De Gracia Roldan, Barcelona, Pediatric Pneumology; Manuel Hernandez, Pere Soler-Palacin, Andrea Martin Nalda, Isabel Caragol, Drahomira Detkova, Fabiola Caracseghi, Núria Murtra Garrell, Barcelona, Vall d'Hebron, Paediatric Infectious Diseases and Immunodeficiencies; Juan Luis, Santos Granada, Hospital Virgen de las Nieves; Rafael Martinez de la Ossa Saenz-Lopez, Granada, Hospital Virgen de las Nieves, Pilar Llobet, Granollers, Hospital General; Luis Ignacio Gonzalez Granado, Madrid, Hospital 12 de octubre; Silvia Sanchez-Ramon, Jose Luis Subiza, Madrid, Hospital Clinico San Carlos; Juana Gil Herrera, Javier Carbone, Eduardo Fernandez-Cruz Perez, Meda Diana Alecsandru, Madrid, Hospital General Universitario Gregorio Maranon; Nuria Matamoros, Natalia Martínez, Mallorca, Hospital Son Dureta (National Centre); Lourdes Tricas, Héctor Suárez Casado, Luis Caminal, Luis Molinos, Eduardo Ramos Oviedo, Hospital Universitario Central de Asturias, Spain; Anders Fasth, Solveig Oskarsdottir, Göteborg University; Janne Björkander, Per Wagström, Helene Jardefors, Jönköping, Ryhov County Hospital; Lennart Hammarström, C.I. Edvard Smith, Ann Gardulf, Anna Berglöf, Peter Bergman, Susanne Hansen, Karolinska, Dept. Laboratory Medicine (Immunbristenheten); Magnus Aurivillius, Lennart Truedsson, Peter Lanbeck, Markus Perlhagen, Göran Jönsson, Ulf Tedgard, Jan Bergils, Nicholas Brodszki, Lund University Hospital; Mikael Sundin, Stockholm, Karolinska University Hospital / Astrid Lindgren Children's Hospital, Sweden; Christoph Hess, Andreas Holbro, Nathan Cantoni, Mary Louise Daly, Basel University Hospital and Kantonsspital Aarau; Ulrich Heininger, Daniela Finke, Urs P. Frey, Basel, Universitäts-Kinderspital beider Basel (UKBB); Arthur Helbling, Urs Steiner, Michaela Bitzenhofer-Grüber, Hatidje Shabanaj, Bern, Inselspital (Erwachsene); Andrea Duppenthaler, Philipp Agyeman, Bern, Inselspital (Kinder); Peter Jandus, Jörg Seebach, Elliot Grange, Geneva, HUG - Service d'Immunologie et d'Allergologie; Hülya Özsahin, Klara 
Posfay Barbe, Geneva, HUG - University Children's Hospital, Pediatric HematoOncology Uni; Johannes Rischewski, Nadia Lanz, Luzern, Kinderspital: Pädiatrische Onkologie u. Hämatologie; Madeleine Bossard, Gaby Fahrni, Pirmin Schmid, Walter Alfred Wuillemin, Thomas Braschler, Luzerner Kantonsspital, Hämatologische Abteilung; Tayfun Güngör, Reinhard Seger, Janine Reichenbach, Barbara Drexel, Miriam Hoernes, Karin Marschall, Zürich, Children's hospital; Thomas Hauser, Zürich, IZZ Immunologie-Zentrum; Adriano Fontana, Ulrike Sahrbacher, Florence Vallelian, Zürich, Universitätsspital, Klinik für Immunologie, Switzerland; Fügen Ersoy, Özden Sanal Tezcan, Ankara, Hacettepe University; Esin Figen Dogu, Aydan Ikinciogullari, Ankara, University School of Medicine; Olcay Yegin, Antalya, Akdeniz University, Faculty of Medicine Hospital, Department of Pediatric Immunology; Güzide Aksu, Necil Kütükcüler, BornovaIzmir, Ege University; Ömür Ardeniz, Bornova-Izmir, Ege University, Medical Faculty; Sara Sebnem Kilic, Mehmet Oker, Bursa-Görükle, University Medical Faculty; Isil B Barlan, Istanbul Marmara University, Pediatric Allergy/Immunology; Ismail Reisli Konya, Necmettin Erbakan University, Turkey; J. David Edgar, Belfast; Aarnoud Huissoon, Birmingham Heartlands; Hilary J. Joyce, Dinakantha Kumararatne, Cambridge, Addenbrooke's Hospital; Andrew Exley, Jane Elliott, Karen Henderson, Helen Gronlund, Helen Baxendale, Cambridge, Papworth NHS Foundation Trust; Mohamed Abuzakouk, Hull Royal Infirmary; Philip Wood, Leeds; Hilary Longhurst, Nichole McIntosh, John Dempster, Michael D. Tarzi, Siamak Arami, Matthew Buckland, London, Barts and the London NHS Trust; Graham Davies, Adrian Thrasher, Paru Naik, Claire Core, Zoe Allwood, Alison Jones, London, Institute of Child Health/Great Ormond Street Hospital; David Aaron Guzman, Sarita Workman, Ronnie Chee, Siobhan Burns, Suranjith Seneviratne, London, Royal Free Hospital, Immunology \& Clin. Pathology; Peter Arkwright, Matthew Helbert, Catherine Bangs, Barbara Boardman, Manchester, Manchester Royal Infirmary; Andrew J. Cant, Andrew R. Gennery, Mary Slatter, Elizabeth Rogerson, Patricia Tierney, Newcastle General Hospital; Helen Chapel, Siraj Misbah, Mary Lucas, Janet Burton, Oxford, U.K.; the Members of the ESID Registry Steering Committee: Matthew Buckland, UCL Centre for Immunodeficiency, Royal Free London NHS Foundation Trust, London, UK; Markus Seidel, Research Unit Pediatric Hematology and Immunology, Division of Pediatric Hematology-Oncology, Department of Pediatrics and Adolescent Medicine, Medical University Graz, Graz, Austria; Joris van Montfrans, Paediatric Immunology, Laboratory of Translational Immunology LTI, University Medical Center Utrecht, Utrecht, The Netherlands; for their review and consent for the publication of the study; the Plasma Protein Therapeutics Association for the financial support of the ESID registry and endorsement of this study; the Members of the PPTA Taskforce: Albert Farrugia, Shanthy Krishnarajah, Joan Mendivil, Mercedes Prior, Tim Rübesam, Michael Runken.

The ESID registry working party

The European Society for Immunodeficiencies (ESID) Registry is based on contributions by the following national registries: CEREDIH (France), REDIP (Spain), PID-NET (Germany), UKPIN (UK), IPINET (Italy), AGPI (Austria), the Netherlands, and Czech Republic. Additional contributions are received from the following countries: Turkey, Poland, Ireland, Iran, Lithuania, Portugal, Belgium, Switzerland, Slovakia, Slovenia, Croatia, Serbia, Greece, Belarus, Russia, Hungary, Romania, Ukraine, Estonia, Egypt, Israel.

\section{Funding}

PPTA sponsored the ESID registry between 2004 and 2014. The principal investigator $1 \mathrm{O}$ completed this study in her position as Director Health Economics \& Outcomes at PPTA and scientific collaborator of Ghent University, Faculty of Medicine and Health Sciences and University of Brussels, Centre de recherche en Economie de la Santé, Gestion des Institutions de Soins et Sciences Infirmières, Ecole de Santé Publique. The funding body did not play a role in the design of the study, data analysis and interpretation or in writing the manuscript.

\section{Availability of data and materials}

Anonymised patient data are available upon request in Excel format. Please contact author for data requests.

\section{Authors' contributions}

All authors read and approved the manuscript. IO conceived the study, coanalysed the dataset and drafted the first version of the manuscript; GK extracted the dataset and was major registry advisor; GK, IQ, NM, PVW and the Plasma Protein Therapeutics Association Taskforce advised on the protocol and the intermediate results; BG, VK, BG and SE were the principle contributors to the establishment and development of the ESID registry; KB performed the statistical analysis; EdV advised on the methodology throughout the project.

\section{Ethics approval and consent to participate}

All included patients signed a consent form for collection and use of their personal data for research purposes: https://esid.org/Working-Parties/ Registry/Informed-Patient-Consent.

\section{Consent for publication}

All included patients signed a consent form giving their permission for the publication of the research results based on the analysis of the collected anonymised data: https://esid.org/Working-Parties/Registry/ Informed-Patient-Consent.

\section{Competing interests}

The authors declare that they have no competing interests.

\section{Publisher's Note}

Springer Nature remains neutral with regard to jurisdictional claims in published maps and institutional affiliations.

\section{Author details}

${ }^{1}$ Plasma Protein Therapeutics Association, Boulevard Brand Whitlock 114b4, 1200 Brussels, Belgium. ${ }^{2}$ Faculty of Medicine and Health Sciences, Ghent University, C. Heymanslaan 10, 9000 Ghent, Belgium. ${ }^{3}$ The ESID Registry Working Partyhttps://esid.org/Working-Parties/Registry. ${ }^{4}$ Center for Chronic Immunodeficiency, Medical Center - University of Freiburg, Faculty of Medicine, University of Freiburg, Freiburg, Germany. ${ }^{5}$ Department of Molecular Medicine, Sapienza University of Rome, Rome, Italy. ${ }^{6}$ University Hospital Policlinico Umberto I, Rome, Italy. Institute of Immunology and Transplantation, Royal Free Hospital, University College London, London, UK. ${ }^{8}$ French National Reference Center for Primary Immune Deficiencies (CEREDIH) and Pediatric Immuno-Haematology and Rheumatology Unit Necker-Enfants Malades University Hospital, Assistance Publique-Hôpitaux de Paris, Paris, France. ${ }^{9}$ Paris Descartes University, Sorbonne Paris Cité, Imagine Institute, Paris, France. ${ }^{10}$ INSERM UMR 1163, Laboratory of Human Genetics of Infectious Diseases, Necker Branch, Paris, France. ${ }^{11}$ Centre de recherche en Economie de la Santé, Gestion des Institutions de Soins et Sciences Infirmières, Ecole de Santé Publique, University of Brussels (ULB), Brussels, Belgium. ${ }^{12}$ Interuniversity Institute for Biostatistics and Statistical Bioinformatics (I-BioStat), KU Leuven - University of Leuven, I-BioStat, 3000 Leuven, Belgium. ${ }^{13}$ University Hasselt, I-BioStat, 3500 Hasselt, Belgium. ${ }^{14}$ Department Tranzo, Tilburg University, PO Box 90153 (RP219), 5000 LE Tilburg, the Netherlands. ${ }^{15}$ Laboratory for Microbiology and Immunology, Elisabeth Tweesteden Hospital, PO Box 90151 (route 90), 5000LC Tilburg, the Netherlands.

Received: 19 June 2018 Accepted: 22 October 2018 Published online: 12 November 2018

\section{References}

1. Orange JS, Glessner JT, Resnick E, Sullivan KE, Lucas M, Ferry B, Kim CE, Hou C, Wang F, Chiavacci R, Kugathasan S, Sleasman JW, Baldassano R, Perez EE, Chapel H, Cunningham-Rundles C, Hakonarson H. Genome-wide association identifies diverse causes of common variable immunodeficiency. J Allergy Clin Immunol. 2011;127(6):1360-7.e6.

2. Chapel H, Lucas M, Lee M, Bjorkander J, Webster D, Grimbacher B, Fieschi C, Thon V, Abedi MR, Hammarstrom L. Common variable immunodeficiency disorders: division into distinct clinical phenotypes. Blood. 2008;112(2):277-86.

3. Bonilla FA, Barlan I, Chapel H, Costa-Carvalho BT, Cunningham-Rundles C, de la Morena MT, Espinosa-Rosales FJ, Hammarström L, Nonoyama S, Quinti I, Routes JM, Tang ML, Warnatz K. International Consensus Document (ICON): Common Variable Immunodeficiency Disorders. J Allergy Clin Immunol Pract. 2016:4(1):38-59.

4. Verma N, Grimbacher B, Hurst JR. Lung disease in primary antibody deficiency. Lancet Respir Med. 2015;3(8):651-60.

5. Ameratunga R, Woon ST, Gillis D, Koopmans W, Steele R. New diagnostic criteria for common variable immune deficiency (CVID), which may assist with decisions to treat with intravenous or subcutaneous immunoglobulin. Clin Exp Immunol. 2013;174(2):203-11. 
6. Westh L, Mogensen TH, Dalgaard LS, Bernth Jensen JM, Katzenstein T, Hansen AE, Larsen OD, Terpling S, Nielsen TL, Larsen CS. Identification and Characterization of a Nationwide Danish Adult Common Variable Immunodeficiency Cohort. Scand J Immunol. 2017;85(6):450-61.

7. Diagnostic criteria of CVID: https://esid.org/Working-Parties/Registry/ Diagnosis-criteria. Accessed on 20 Oct 2017.

8. Yang L, Wu EY, Tarrant TK Immune Gamma Globulin Therapeutic Indications in Immune Deficiency and Autoimmunity. Curr Allergy Asthma Rep. 2016;16(8):55.

9. Chapel H, Cunningham-Rundles C. Update in understanding common variable immunodeficiency disorders (CVIDs) and the management of patients with these conditions. Br J Haematol. 2009;145(6):709-27.

10. Quinti I, Soresina A, Spadaro G, Martino S, Donnanno S, Agostini C, Claudio P, Franco D, Maria Pesce A, Borghese F, Guerra A, Rondelli R, Plebani A, Italian Primary Immunodeficiency Network. Long-term follow-up and outcome of a large cohort of patients with common variable immunodeficiency. J Clin Immunol. 2007;27(3):308-16.

11. Gathmann B, Mahlaoui N; CEREDIH, Gérard L, Oksenhendler E, Warnatz K, Schulze I, Kindle G, Kuijpers TW; Dutch WID, van Beem RT, Guzman D, Workman S, Soler-Palacín P, De Gracia J, Witte T, Schmidt RE, Litzman J. Hlavackova E, Thon V, Borte M, Borte S, Kumararatne D, Feighery C, Longhurst H, Helbert M, Szaflarska A, Sediva A, Belohradsky BH, Jones A, Baumann U, Meyts I, Kutukculer N, Wågström P, Galal NM, Roesler J, Farmaki E, Zinovieva N, Ciznar P, Papadopoulou-Alataki E, Bienemann K, Velbri S, Panahloo Z, Grimbacher B; European Society for Immunodeficiencies Registry Working Party. Clinical picture and treatment of 2212 patients with common variable immunodeficiency. J Allergy Clin Immunol 2014;134(1):116-126.

12. Pandit C, Hsu P, van Asperen P, Mehr S. Respiratory manifestations and management in children with Common Variable Immunodeficiency. Paediatr Respir Rev. 2016;19:56-61.

13. Maglione PJ. Autoimmune and Lymphoproliferative Complications of Common Variable Immunodeficiency. Curr Allergy Asthma Rep. 2016;16(3):19.

14. Oksenhendler E, Gérard L, Fieschi C, Malphettes M, Mouillot G, Jaussaud R, Viallard JF, Gardembas M, Galicier L, Schleinitz N, Suarez F, Soulas-Sprauel P, Hachulla E, Jaccard A, Gardeur A, Théodorou I, Rabian C, Debré P, DEFL study group. Infections in 252 patients with common variable immunodeficiency. Clin Infect Dis. 2008:46(10):1547-54.

15. Lucas M, Lee M, Lortan J, Lopez-Granados E, Misbah S, Chapel H. Infection outcomes in patients with common variable immunodeficiency disorders: relationship to immunoglobulin therapy over 22 years. J Allergy Clin Immunol. 2010:125(6):1354-1360.e4

16. Orange JS, Grossman WJ, Navickis RJ, Wilkes MM. Impact of trough IgG on pneumonia incidence in primary immunodeficiency: A meta-analysis of clinical studies. Clin Immunol. 2010;137(1):21-30.

17. Perez EE, Orange JS, Bonilla F, Chinen J, Chinn IK, Dorsey M, El-Gamal Y, Harville TO, Hossny E, Mazer B, Nelson R, Secord E, Jordan SC, Stiehm ER, Vo AA, Ballow M. Update on the use of immunoglobulin in human disease: A review of evidence. J Allergy Clin Immunol. 2017;139(3S):S1-S46.

18. Hypogammaglobulinaemia in the United Kingdom. Summary report of a Medical Research Council working-party. Lancet. 1969;1(7587):163-8.

19. Busse PJ, Razvi S, Cunningham-Rundles C. Efficacy of intravenous immunoglobulin in the prevention of pneumonia in patients with common variable immunodeficiency. J Allergy Clin Immunol. 2002;109(6):1001-4.

20. Aghamohammadi A, Pouladi N, Parvaneh N, Yeganeh M, Movahedi M, Gharagolou M, Pourpak Z, Rezaei N, Salavati A, Abdollahzade S, Moin M. Mortality and morbidity in common variable immunodeficiency. J Trop Pediatr. 2007;53(1):32-8.

21. Murray CJ, Barber RM, Foreman KL, et al. Global, regional, and national disability-adjusted life years (DALYs) for 306 diseases and injuries and healthy life expectancy (HALE) for 188 countries, 1990-2013: quantifying the epidemiological transition. Lancet. 2015;386:2145-91.

22. Grimbacher B, ESID registry working party. The European Society for Immunodeficiencies (ESID) registry 2014. Clin Exp Immunol. 2014; 178(Suppl 1):18-20.

23. The World Health Organization Child Growth Statistics. http://www.who.int/ childgrowth/standards/Technical_report.pdf. Accessed on 20 Oct 2017.

24. Institute for Health Metrics and Evaluation of the University of Washington. GBD Results Tool: http.//ghdx.healthdata.org/gbd-results-tool. Accessed on 20 Oct 2017.

25. Salomon JA, Vos T, Hogan DR, Gagnon M, Naghavi M, et al. Common values in assessing health outcomes from disease and injury: disability weights measurement study for the Global Burden of Disease Study 2010. Lancet. 2012;380(9859):2129-43.
26. US Food and Drug Administration guidance:https:/www.fda.gov/ biologicsbloodvaccines/guidancecomplianceregulatoryinformation/ guidances/blood/ucm072130.htm. Accessed on 20 Oct 2017.

27. GBD 2013 Mortality and Causes of Death Collaborators. Global, regional, and national age-sex specific all-cause and cause-specific mortality for 240 causes of death, 1990-2013: a systematic analysis for the Global Burden of Disease Study 2013. Lancet. 2015;385(9963):117-71.

28. Annemans L, Aymé S, Le Cam Y, Facey K, Gunther P, Nicod E, Reni M, Roux JL, Schlander M, Taylor D, Tomino C, Torrent-Farnell J, Upadhyaya S, Hutchings A, Le Dez L. Recommendations from the European working Group for Value Assessment and Funding Processes in rare diseases (ORPHVAL). Orphanet J Rare Dis. 2017;12(1):50.

29. Quinti I, Soresina A, Guerra A, Rondelli R, Spadaro G, Agostini C, Milito C, Trombetta AC, Visentini M, Martini H, Plebani A, Fiorilli M, IPINet Investigators. Effectiveness of immunoglobulin replacement therapy on clinical outcome in patients with primary antibody deficiencies: results from a multicenter prospective cohort study. J Clin Immunol. 2011;31(3):315-22.

30. Resnick ES, Moshier EL, Godbold JH, Cunningham-Rundles C. Morbidity and mortality in common variable immune deficiency over 4 decades. Blood. 2012;119(7):1650-7.

31. Graziano V, Pecoraro A, Mormile I, Quaremba G, Genovese A, Buccelli C, Paternoster M, Spadaro G. Delay in diagnosis affects the clinical outcome in a cohort of cvid patients with marked reduction of iga serum levels. Clin Immunol. 2017;180:1-4.

32. O'Sullivan MD, Cant AJ. The 10 warning signs: a time for a change? Curr Opin Allergy Clin Immunol. 2012;12(6):588-94.

33. Arslan S, Ucar R, Caliskaner AZ, Reisli I, Guner SN, Sayar EH, Baloglu I. How effective are the 6 European Society of Immunodeficiency warning signs for primary immunodeficiency disease? Ann Allergy Asthma Immunol. 2016; 116(2):151-155.e1.

34. Reda SM, El-Ghoneimy DH, Afifi HM. Clinical predictors of primary immunodeficiency diseases in children. Allergy Asthma Immunol Res. 2013;5(2):88-95.

35. Orange JS, Seeborg FO, Boyle M, Scalchunes C, Hernandez-Trujillo V. Family Physician Perspectives on Primary Immunodeficiency Diseases. Front Med (Lausanne). 2016;3:12.

36. Modell V, Gee B, Lewis DB, Orange JS, Roifman CM, Routes JM, Sorensen RU, Notarangelo LD, Modell F. Global study of primary immunodeficiency diseases (PI)--diagnosis, treatment, and economic impact: an updated report from the Jeffrey Modell Foundation. Immunol Res. 2011;51(1):61-70.

37. Al-Herz W, Aldhekri H, Barbouche MR, Rezaei N. Consanguinity and primary immunodeficiencies. Hum Hered. 2014;77(1-4):138-43.

38. Al-Herz W, Moussa MA. Survival and predictors of death among primary immunodeficient patients: a registry-based study. J Clin Immunol. 2012; 32(3):467-73.

39. Rezaei N, Pourpak Z, Aghamohammadi A, Farhoudi A, Movahedi M, Gharagozlou M, Mirsaeid Ghazi B, Atarod L, Abolmaali K, Mahmoudi M, Mansouri D, Arshi S, Tarash NJ, Sherkat R, Amin R, Kashef S, Hosseini RF, Mohammadzadeh I, Shabestari MS, Nabavi M, Moin M. Consanguinity in primary immunodeficiency disorders; the report from Iranian Primary Immunodeficiency Registry. Am J Reprod Immunol. 2006;56(2):145-51.

40. Mahlaoui N, Warnatz K, Jones A, Workman S, Cant A. Advances in the Care of Primary Immunodeficiencies (PIDs): from Birth to Adulthood. J Clin Immunol. 2017;37(5):452-60.

41. Leone P, Vacca A, Dammacco F, Racanelli V. Common variable immunodeficiency and gastric malignancies. Int J Mol Sci. 2018 Feb 2;19(2).

42. Berger M. Choices in IgG replacement therapy for primary immune deficiency diseases: subcutaneous IgG vs. intravenous IgG and selecting an optimal dose. Curr Opin Allergy Clin Immunol. 2011; 11(6):532-8.

43. Walsh JE, Gurrola JG 2nd, Graham SM, Mott SL, Ballas ZK. Immunoglobulin replacement therapy reduces chronic rhinosinusitis in patients with antibody deficiency. Int Forum Allergy Rhinol. 2017;7(1):30-6.

44. Prevalence of Gastric Cancer: http://globocan.iarc.fr/old/FactSheets/cancers/ stomach-new.asp. Accessed on 14 Feb 2018.

45. Quinti I, Agostini C, Tabolli S, Brunetti G, Cinetto F, Pecoraro A, Spadaro G. Malignancies are the major cause of death in patients with adult onset common variable immunodeficiency. Blood. 2012;120(9):1953-4.

46. Barlogis V, Mahlaoui N, Auquier P, Pellier I, Fouyssac F, Vercasson C, Allouche M, De Azevedo CB, Suarez F, Moshous D, Neven B, Pasquet M, 
Jeziorski E, Aladjidi N, Schleinitz N, Thomas C, Gandemer V, Mazingue F, Lutz P, Hermine O, Picard C, Blanche S, Michel G, Fischer A. Physical health conditions and quality of life in adults with primary immunodeficiency diagnosed during childhood: a French reference center for PIDs (CEREDIH) study. J Allergy Clin Immunol. 2017;139(4):1275-81.

47. Quinti I, Pulvirenti F, Giannantoni P, Hajjar J, Canter DL, Milito C, Abeni D, Orange JS, Tabolli S. Development and initial validation of a questionnaire to measure health-related quality of life of adults with common variable immune deficiency: the CVID_QoL questionnaire. J Allergy Clin Immunol Pract. 2016;4(6):1169-79.

48. Malphettes M, Gérard L, Carmagnat M, Mouillot G, Vince N, Boutboul D, Bérezné A, Nove-Josserand R, Lemoing $V$, Tetu L, Viallard JF, Bonnotte B, Pavic M, Haroche J, Larroche C, Brouet JC, Fermand JP, Rabian C, Fieschi C, Oksenhendler E. DEFI study group.. Late-onset combined immune deficiency: a subset of common variable immunodeficiency with severe T cell defect. Clin Infect Dis. 2009;49(9):1329-38.

49. Chapel H. Common variable immunodeficiency disorders (CVID) - diagnoses of exclusion, especially combined immune defects. J Allergy Clin Immunol Pract. 2016;4(6):1158-9.

50. Bertinchamp R, Gérard L, Boutboul D, Malphettes M, Fieschi C, Oksenhendler E, DEFI study group. Exclusion of Patients with a Severe T-Cell Defect Improves the Definition of Common Variable Immunodeficiency. J Allergy Clin Immunol Pract. 2016;4(6):1147-57.

Ready to submit your research? Choose BMC and benefit from:

- fast, convenient online submission

- thorough peer review by experienced researchers in your field

- rapid publication on acceptance

- support for research data, including large and complex data types

- gold Open Access which fosters wider collaboration and increased citations

- maximum visibility for your research: over $100 \mathrm{M}$ website views per year

At BMC, research is always in progress.

Learn more biomedcentral.com/submissions 